University of Wollongong

Research Online

Australian Institute for Innovative Materials -

Papers

Australian Institute for Innovative Materials

$1-1-2018$

\title{
Giant enhancement of the figure-of-merit over a broad temperature range in nano-boron incorporated Cu2Se
}

Sheik Md. Kazi Nazrul Islam

University of Wollongong, smkni979@uowmail.edu.au

Meng Li

University of Wollongong, ml886@uowmail.edu.au

Umut Aydemir

Koc University

Xun Shi

Chinese Academy of Sciences

Lidong Chen

Chinese Academy Of Sciences

See next page for additional authors

Follow this and additional works at: https://ro.uow.edu.au/aiimpapers

Part of the Engineering Commons, and the Physical Sciences and Mathematics Commons

Research Online is the open access institutional repository for the University of Wollongong. For further information contact the UOW Library: research-pubs@uow.edu.au 


\title{
Giant enhancement of the figure-of-merit over a broad temperature range in nano-boron incorporated Cu2Se
}

\author{
Abstract \\ Superionic conductors in the chalcogenide-based copper selenide family have been considered as a \\ promising class of thermoelectric materials, which offer great prospects for converting ubiquitous waste \\ heat into highly demanded electrical energy. Further improvement of the thermoelectric figure-of-merit, zT, \\ for Cu2Se is very desirable for its practical applications. Since any enhancement in electrical conductivity \\ is often accompanied by a reduction in the Seebeck coefficient or thermal power or vice versa, a \\ significant reduction of thermal conductivity becomes an important strategy for improvement of zT. In \\ this work, we demonstrate that insulating-boron nano-particle inclusion in Cu2Se has little effect on the \\ overall power factor but can significantly reduce the thermal conductivity, resulting in great improvement \\ in zT, by a factor of 1.6-2.6 compared to undoped samples over a wide range of temperatures. \\ Microstructure studies by high resolution transmission electron microscopy revealed that boron \\ nanostructures interspaced between Cu2Se microscale grains are responsible for the great reduction in \\ thermal conductivity and, in turn, the significantly enhanced $\mathrm{zT}$. The enhancement of thermal boundary \\ resistance ascribed to the strong acoustic mismatch between Cu2Se and boron is responsible for the low \\ thermal conductivity of the microstructured composite. Our findings offer an effective approach of using \\ insulating nano-particles to significantly improve the Seebeck coefficient and significantly reduce lattice \\ thermal conductivity for achieving high zT in Cu2Se and many other similar thermoelectric composites.

\section{Disciplines} \\ Engineering | Physical Sciences and Mathematics

\section{Publication Details} \\ Nazrul Islam, S., Li, M., Aydemir, U., Shi, X., Chen, L., Snyder, G. Jeffrey. \& Wang, X. (2018). Giant \\ enhancement of the figure-of-merit over a broad temperature range in nano-boron incorporated Cu2Se. \\ Journal of Materials Chemistry A, 6 (38), 18409-18416.

\section{Authors} \\ Sheik Md. Kazi Nazrul Islam, Meng Li, Umut Aydemir, Xun Shi, Lidong Chen, G Jeffrey Snyder, and Xiaolin \\ Wang
}




\title{
Giant enhancement of the figure-of-merit over a broad temperature range in nano-boron incorporated $\mathrm{Cu}_{2} \mathrm{Se}^{ \pm}$
}

Sheik Md. Kazi Nazrul Islam ${ }^{a}$, Meng Li ${ }^{a}$, Umut Aydemir ${ }^{c}$, Xun Shi ${ }^{d}$, Lidong Chen ${ }^{\text {d }}$, G Jeffrey Snyder ${ }^{\mathrm{e}}$, and Xiaolin Wang ${ }^{* a b}$

* Corresponding authors

${ }^{a}$ Institute for Superconducting and Electronic Materials, Australian Institute for Innovative Materials, University of Wollongong, North Wollongong, NSW 2500, Australia, E-mail: xiaolin@uow.edu.au

${ }^{\mathrm{b}}$ ARC Centre of Excellence in Future Low-Energy Electronics Technologies, University of Wollongong, Australia

${ }^{c}$ Department of Chemistry, Koc University, Sariyer, Istanbul, 34450, Turkey

d State Key Laboratory of High Performance Ceramics and Superfine Microstructures, Shanghai Institute of Ceramics, Chinese Academy of Sciences, 1295 Dingxi Road, Shanghai, China, 200050

e Northwestern University, 2220 Campus Drive, Cook Hall, Evanston, IL 60208-3109, USA

\begin{abstract}
Superionic conductors in the chalcogenide-based copper selenide family have been considered as a promising class of thermoelectric materials, which offer great prospects for converting ubiquitous waste heat into highly demanded electrical energy. Further improvement of the thermoelectric figure-of-merit, $z T$, for $\mathrm{Cu}_{2} \mathrm{Se}$ is very desirable for its practical applications. Since any enhancement in electrical conductivity is often accompanied by a reduction in the Seebeck coefficient or thermal power or vice versa, a significant reduction of thermal conductivity becomes an important strategy for improvement of $z T$. In this work, we demonstrate that insulating-boron nano-particle inclusion in $\mathrm{Cu}_{2} \mathrm{Se}$ has little effect on the overall power factor but can significantly reduce the thermal conductivity, resulting in great improvement in $z T$, by a factor of 1.6-2.6 compared to undoped samples over a wide range of temperature. Microstructure studies by high resolution transmission
\end{abstract}


electron microscopy revealed that boron nanostructures interspaced between $\mathrm{Cu}_{2} \mathrm{Se}$ microscale grains are responsible for the great reduction in thermal conductivity and, in turn, the significantly enhanced $z T$. The enhancement of thermal boundary resistance ascribed to the strong acoustic mismatch between $\mathrm{Cu}_{2} \mathrm{Se}$ and boron is responsible for the low thermal conductivity of the microstructured composite. Our findings offer an effective approach of using insulating nano-particles to significantly improve the Seebeck coefficient and significantly reduce lattice thermal conductivity for achieving high $z T$ in $\mathrm{Cu}_{2} \mathrm{Se}$ and many other similar thermoelectric composites.

\section{Introduction}

Thermoelectric (TE) technology offers a simple and environment-friendly solution for directly recovering waste heat as usable electricity leading to reduction in the global energy crisis. ${ }^{1-3}$ These devices operate with high reliability, with no moving parts or emission of greenhouse gasses. ${ }^{4}$ TE materials are classified with respect to their intended operating temperature range, with applications varying from spacecraft ${ }^{5}$ to harvesting waste heat from industrial appliances ${ }^{6}$ and automobile exhaust systems. ${ }^{7}$ The figure of merit, $z T=$ $\left(\sigma S^{2}\right) /\left(\kappa_{\text {Lat }}+\kappa_{\text {ele }}\right) T$, is the key factor for the energy conversion efficiency of thermoelectric generators, where $\sigma, S, \kappa_{\text {lat }}, \kappa_{\text {elec }}, T$ are the electrical conductivity, Seebeck coefficient, lattice thermal conductivity, charge carrier thermal conductivity, and absolute temperature, respectively. The total thermal conductivity $(\kappa)$ expressed by $\kappa=\kappa_{\text {lat }}+\kappa_{\text {ele }}$, is mainly dominated by lattice vibrations compared to those of the charge carriers at high temperature. Since there are strong correlations between thermal and electrical transport in solids, achieving high $z T$ is extremely challenging. So, optimizing the interdependent transport coefficients $\kappa, \sigma$, and $S$ has been the key focus in research to improve $z T$. The following techniques have been successfully implemented so far to enhance $z T$ in a wide range of high-temperature TE materials: 1) substitution that changes $\sigma$ due to carrier 
concentration as well as $\kappa$ due to different atomic masses; 2) reduction of particle size by a nano-engineering approach, which gives rise to confinement of both intragrain and intergrain phonons; 3) reducing the dimensionality of TE materials by creating multilayer thin films; and 4) introducing inclusion of a secondary phase that does not change the carrier concentration, but does reduce $\kappa$ due to the blocking of phonons.

Among all the $\mathrm{Cu}$-based $\mathrm{TE}$ materials, $\mathrm{Cu}_{2} \mathrm{Se}$ has received great attention recently, as it has good thermoelectric performance. To date, the electronic structures and thermal conductivity of $\mathrm{Cu}_{2} \mathrm{Se}$ have been modified by doping using $\mathrm{Al}, \mathrm{Sn}, \mathrm{Sb}, \mathrm{Ag}$, and $\mathrm{Li}$ in the $\mathrm{Cu}$ sites ${ }^{8-12}$, and Te, S, I, and $\mathrm{Br}$ in the Se sites. ${ }^{13-16}$ Recently, it has been reported that various types of carbon incorporated $\mathrm{Cu}_{2} \mathrm{Se}$ composites exhibited high $z T$ of $\sim 1.8-2.4$ at $850 \mathrm{~K}^{17-19}$ using a melt fabrication process above the melting point of $\mathrm{Cu}_{2} \mathrm{Se}^{20}$ The key factor for the great enhancement of $z T$ by carbon incorporation is the giant reduction of thermal conductivity. Since any enhancement in electrical conductivity is often accompanied by a reduction in the Seebeck coefficient or thermal power or vice versa, a significant reduction of thermal conductivity becomes an important strategy for improvement of $z T$. In this work, we propose to use another non-toxic, lightweight, but insulating dopant, boron nano-particles, to incorporate into $\mathrm{Cu}_{2} \mathrm{Se}$. It is also well known that boron (B) doping provides remarkable stability in corrosive and acidic environments and improves mechanical stability. ${ }^{21-26}$

In this Communication, we report that using the light element boron as a second nanophase in the $\mathrm{Cu}_{2} \mathrm{Se}$ can give significantly enhanced thermoelectric performance. We demonstrate that boron addition can remarkably reduce $\kappa$ and enhances $S$ preserving high power factor over a wide range of temperatures, leading to the enhancement of $z T$ by a factor of 1.6 - 2.6 compared to undoped samples over a wide temperature range (450-850 K). 


\section{Results and discussion}

The fabrication process for the boron doped $\mathrm{Cu}_{2} \mathrm{Se}$ is illustrated by schematic representation in Fig. 1 and details are mentioned in sample preparation section. Fig. S1 in the ESII shows the $\mathrm{Cu}_{2} \mathrm{Se}$ structure, with the monoclinic $\alpha$-phase (left side) at room temperature and the cubic $\beta$-phase (right side) at high temperature, respectively. Powder X-ray diffraction (XRD) patterns (Fig. 2b) shows that the boron doped samples at room temperature is $\alpha$-phase. We noted that peak positions slightly change with boron nanoparticle inclusions. They all shifted to small 2-theta values (Fig. $2 b)$ indicating that the lattice parameters are likely to decrease due to boron inclusion. The peak intensity at $37 \mathrm{deg}$ (2-theta) decreases and disappears at high boron contents. There is another remarkable change in peaks as shown in the middle and right figures of Fig. 2c. The shoulder peaks gradually disappear with B addition. These results may suggest that higher boron contents tend to stabilize another crystal structure. ${ }^{27}$ A Synchrotron high temperature (HT) experiment was performed on both the undoped and boron doped samples (Fig. S3a$\mathrm{h} \doteq$ ). Overall this may indicate that B doping may stabilize the HT cubic phase (Fig. S3b $₫$ ). A further detailed study using high temperature TEM is needed to identify the possible boronstabilized phases.

Temperature-dependent synchrotron powder X-ray diffraction was performed in order to further investigate the boron doping effect over the change of phase transition with temperature and to identify the change in lattice parameters with temperature. Heat-map images with respect to temperature of undoped $\mathrm{Cu}_{2} \mathrm{Se}$ and a $0.42 \mathrm{wt} \%$ nano-boron doped $\mathrm{Cu}_{2} \mathrm{Se}$ sample from room temperature to $774 \mathrm{~K}$ are shown in Fig. $3 \mathrm{a}$ and b, respectively. The mapping shows that there are $\alpha$ to $\beta$ phase transitions for both undoped and boron doped $\mathrm{Cu}_{2} \mathrm{Se}$ within this temperature range. This transformation can also be observed in differential scanning calorimetry (DSC) measurements (Fig. 3c), where the phase transition takes place at 
$400 \mathrm{~K}$ for undoped $\mathrm{Cu}_{2} \mathrm{Se}$ and $417 \mathrm{~K}$ for $0.42 \mathrm{wt} \%$ boron doped $\mathrm{Cu}_{2} \mathrm{Se}$. Possible boron substitution effect and any atom deficiency might contribute to the phase transition shift.

The Rietveld refinements and high-resolution synchrotron XRD data of undoped and 0.42 wt\% boron doped $\mathrm{Cu}_{2} \mathrm{Se}$ samples are shown in Fig. $\mathrm{S} 2$ and $\mathrm{S} 3, \pm$ respectively. The lattice parameters and R-factors of the undoped and boron doped $\mathrm{Cu}_{2} \mathrm{Se}$ samples deduced from the Rietveld refinement of the synchrotron XRD patterns are listed in Tables S1I, respectively. We found that lattice parameter for the boron doped $\mathrm{Cu}_{2} \mathrm{Se}$ has $5.8507 \AA$, $5.8388 \AA$, $5.8277 \AA$ whereas it was observed to be $5.8611 \AA$, $5.8427 \AA$ and $5.8316 \AA$ at $624 \mathrm{~K}, 512 \mathrm{~K}$ and $403 \mathrm{~K}$, respectively for the undoped sample. From this result, we can see that lattice parameter variations with boron doping is obvious and it further indicates that there is a boron doping effect in $\mathrm{Cu}_{2} \mathrm{Se}$. We note that the XRD patterns recorded before and after heating and cooling are almost identical for both undoped and doped samples (Fig. 3d), indicating that the phase transformation process is reversible. This also confirms that the boron doped samples have good thermal stability, which is in conformity with the reproducibility of $\sigma, S$, and the thermal diffusivity $(D)$ (Fig. S7立).

Field emission scanning electron microscope (FE-SEM) images of the boron doped $\mathrm{Cu}_{2} \mathrm{Se}$ and pure $\mathrm{Cu}_{2} \mathrm{Se}$ bulks are shown in Fig. S4 $\mathrm{I}$. All the samples were found to be highly dense with no porosity. The processed high-angle annular dark field - scanning transmission electron microscope (HAADF-STEM) images of monoclinic $\mathrm{Cu}_{2} \mathrm{Se}$, their ball models and selected area electron diffraction (SAED) pattern are presented in Fig. 4.

Fig. 4a shows the structure of boron doped $\mathrm{Cu}_{2} \mathrm{Se}$ as determined from the HAADF-STEM image (Fig. 4b). The signal-to-noise ratio of the image was improved by using an average filter. The top inset (Fig. 4b) is the distance profile of Se-Se along the marked dotted yellow lines A and B in the image, showing that the space between Se and Se is around $0.899 \mathrm{~nm}$. The bottom inset (Fig. 4b) shows the corresponding atomic model, indicating a perfect 
monoclinic structure along the $\left[\begin{array}{lll}0 & -1 & 0\end{array}\right]$ orientation. Due to the very much lower $\mathrm{Z}$ contrast of B (atomic number contrast), it is impossible to distinguish B atoms in the HAADF-STEM image from the $\left[\begin{array}{lll}0 & -1 & 0\end{array}\right]$ orientation. Fig. 4c presents the SAED pattern along the $\left[\begin{array}{lll}0 & -1 & 0\end{array}\right]$ orientation. Transmission electron microscope (TEM) images and the high resolution TEM images show (Fig. 4d-e) the boron regions, which appear as black patches and dots embedded inside the $\mathrm{Cu}_{2} \mathrm{Se}$ grains, as determined by energy dispersive spectroscopy (EDS) mapping. The presence of boron inclusions across the grain boundary is also shown in Fig. S5t. We can see that the average boron particle sizes are as small as $80 \mathrm{~nm}$. This may indicate that most of the boron precipitates at the grain boundaries but it is likely that a small amount of boron goes into the lattice for causing the lattice parameter to reduce. These nano-boron inclusions are expected to play a significant role in blocking the phonons.

We studied the effects of nano-boron addition on the $\sigma, S$, and $\kappa$, as well as the microhardness. The temperature dependence of $\sigma, S, \kappa$, and $z T$ for an undoped and boron doped $\mathrm{Cu}_{2} \mathrm{Se}$ samples is shown in Fig. 5. The $\sigma$ of all samples decreases with increasing temperature over the whole temperature range (Fig. 5a). We can see that the boron-doped $\mathrm{Cu}_{2} \mathrm{Se}$ sample shows lower electrical conductivity than the undoped sample for both $\alpha$ - and $\beta$-phases. This trend becomes more obvious for high boron doping levels. The electrical conductivity is reduced from $\sim 458 \mathrm{~S} \mathrm{~cm}^{-1}$ for the undoped sample to $207 \mathrm{~S} \mathrm{~cm}^{-1}$ for the 0.42 wt $\%$ boron doped $\mathrm{Cu}_{2} \mathrm{Se}$ at $852 \mathrm{~K}$. The carrier concentration $p$ and mobility $\mu_{H}$ were determined using Hall effect measurements using the formula: $p=1 /\left(e R_{H}\right)$, where $e$ represents the elemental charge and $R_{H}$ the Hall coefficient. We found from the Hall effect measurements that hole concentration $(p)$ for the pure $\mathrm{Cu}_{2} \mathrm{Se}, 0.28 \mathrm{wt} \% \mathrm{~B}$ and $0.42 \mathrm{wt} \% \mathrm{~B}$ is $6.17 \times 10^{20} \mathrm{~cm}^{-3}, 5.6 \times 10^{20} \mathrm{~cm}^{-3}$ and $3.92 \times 10^{20} \mathrm{~cm}^{-3}$, respectively. The mobility $\left(\mu_{H}\right)$ for the pure $\mathrm{Cu}_{2} \mathrm{Se}, 0.28 \mathrm{wt} \% \mathrm{~B}$ and $0.42 \mathrm{wt} \% \mathrm{~B}$ are $11.11 \mathrm{~cm}^{2} \mathrm{~V}^{-1} \mathrm{~S}^{-1}$, $5.73 \mathrm{~cm}^{2} \mathrm{~V}^{-1} \mathrm{~S}^{-1}$ and $\sim 5 \mathrm{~cm}^{2} \mathrm{~V}^{-1} \mathrm{~S}^{-1}$, respectively. The hole carrier concentration decreases 
with the amount of boron and for the $0.42 \mathrm{wt} \%$ boron doped samples it is $\sim 37 \%$ lower than that of the pure $\mathrm{Cu}_{2} \mathrm{Se}$. This result is consistent with the electrical conductivity and Seebeck coefficient measurements. This may indicate that either B dope into the $\mathrm{Cu}$ sites or fill the $\mathrm{Cu}$ vacancies. Both can lead to a decrease in the carrier concentration. The carrier mobility $\mu_{H}$ for the $0.42 \mathrm{wt} \% \mathrm{~B}$ doped sample is $\sim 5 \mathrm{~cm}^{2} \mathrm{~V}^{-1} \mathrm{~S}^{-1}$, which is about $54 \%$ lower than for the undoped $\mathrm{Cu}_{2} \mathrm{Se}$ (Fig. 5d). As $\sigma=n e \mu_{H}$, where $\mathrm{n}$ is the carrier concentration, the overall reduction in $\sigma$ is mainly caused by the decreased hole concentration as well as carrier mobility in the B added sample. In addition, the electron scattering occurring at the boron/ $\mathrm{Cu}_{2} \mathrm{Se}$ interface may also play an important role in reducing the $\sigma$.

The reduction in electrical conductivity is often accompanied by enhancement of the Seebeck coefficient. Fig. 5b shows the temperature dependence of the Seebeck coefficient for both boron doped and undoped samples. It can be seen that $S$ increases with boron doping over a wide range of temperatures. For the $0.42 \mathrm{wt} \%$ boron doped $\mathrm{Cu}_{2} \mathrm{Se}$, the maximum $S$ value is $245 \mu \mathrm{V} \mathrm{K}^{-1}$ at $852 \mathrm{~K}$, which is about $48 \%$ higher than that of the undoped sample.

The power factor $(\mathrm{PF})=\sigma S^{2}$ is $6-10 \times 10^{-4} \mathrm{Wm}^{-1} \cdot \mathrm{K}^{-2}$ for the undoped $\alpha$-phase and $6.6-12.7 \times 10^{-4} \mathrm{Wm}^{-1} \cdot \mathrm{K}^{-2}$ for the $\beta$-phase, which is almost same as in the previously reported results (Fig. 5c). ${ }^{13,28}$ All the boron-doped samples show the same trend in the power factor with increasing temperature, and the highest values obtained were $10-12 \times$ $10^{-4} \mathrm{Wm}^{-1} \cdot \mathrm{K}^{-2}$ for the $\alpha$-phase and $9-12.4 \times 10^{-4} \mathrm{Wm}^{-1} \cdot \mathrm{K}^{-2}$ for the $\beta$-phase of 0.42 wt $\% \mathrm{~B}$ doped $\mathrm{Cu}_{2} \mathrm{Se}$. Although there was no significant difference at high temperature, the latter one is about $39 \%$ larger as compared to the pristine $\mathrm{Cu}_{2} \mathrm{Se}$ sample at $456 \mathrm{~K}$. In this case, our expectations of any enhancement in $z T$ completely rely on whether or not the thermal conductivity can be reduced by the boron nano-inclusions.

Remarkably, the boron doped $\mathrm{Cu}_{2} \mathrm{Se}$ samples exhibit greatly reduced thermal conductivity compared to the boron-free sample, as displayed in Fig. 5e over a temperature range from 
$300-850 \mathrm{~K}$. The $\kappa$ for the undoped sample is $1.4-1.08 \mathrm{Wm}^{-1} \cdot \mathrm{K}^{-1}$ from $456 \mathrm{~K}-852 \mathrm{~K}$, while the value is as small as $\sim 0.66 \mathrm{~W} \cdot \mathrm{m}^{-1} \cdot \mathrm{K}^{-1}$ for the $0.42 \mathrm{wt} \%$ boron doped $\mathrm{Cu}_{2} \mathrm{Se}$ over the whole temperature range. This value is half of the value for the undoped sample and is also the lowest among almost all the undoped $\mathrm{Cu}_{2} \mathrm{Se}$ samples reported so far. ${ }^{12,14,15,28-30}$ The microstructure and phonon transport property of the boron precipitated microcomposite $\mathrm{Cu}_{2} \mathrm{Se}$ samples (average grain size $0.4 \mu \mathrm{m}$ ) are illustrated in Fig. 5f. The reduction of thermal conductivity and enhancement of the thermoelectric figure-of-merit are absolutely due to boron.

The $z T$ is found to increase with boron doping concentration for all temperatures (Fig. 6a). The $z T$ is 1.0 at $T=600 \mathrm{~K}$ and reaches 1.6 at $852 \mathrm{~K}$ for the $0.42 \mathrm{wt} \%$ boron doped sample as compared to the $z T$ of 0.46 at $600 \mathrm{~K}$ and 0.99 at $852 \mathrm{~K}$ for the undoped sample. It is remarkable that the overall $z T$ enhancement ratio is 1.6 to 2.6 for the optimum boron doped sample compared to the undoped one (Fig. S6+). The efficiency is calculated according to the literature. ${ }^{31}$ It was found that efficiency is $\sim 15 \%$ at $852 \mathrm{~K}$ for the $0.42 \mathrm{wt} \% \mathrm{~B}$ sample, whereas it is only $9.4 \%$ for the undoped $\mathrm{Cu}_{2} \mathrm{Se}$ at $852 \mathrm{~K}$ (Fig. 6b).

We calculated $\kappa_{e l e}$ according to the Wiedemann-Franz law $\left(\kappa_{\text {ele }}=L \sigma T\right)$, where $L$ represents the Lorentz number. In this work, $L$ is calculated according to the equation $L=1.5+\exp [-|S| / 116]$, where $L$ is in $10^{-8} \mathrm{~W} \Omega \cdot \mathrm{K}^{-2}$ and $\mathrm{S}$ in $\mu \mathrm{V} \cdot \mathrm{K}^{-1} \cdot{ }^{32,}{ }^{33}$ The calculated results show that $L$ varies in the range of $(1.6-2) \times 10^{-8} \mathrm{~W} \Omega \cdot \mathrm{K}^{-2}$ with different types of boron doping and with the temperature increasing from 350 to $852 \mathrm{~K}$ (Fig. 7a). The total $\kappa$ in Fig. $7 \mathrm{~b}$ shows a decrease to $\sim 0.66-0.73 \mathrm{~W} \mathrm{~m}^{-1} \mathrm{~K}^{-1}$ with temperature for the $0.42 \mathrm{wt} \%$ boron doped $\mathrm{Cu}_{2} \mathrm{Se}$, while it was $\sim 1.08-1.40 \mathrm{~W} \mathrm{~m}^{-1} \mathrm{~K}^{-1}$ for the undoped $\mathrm{Cu}_{2} \mathrm{Se}$. The calculated $\kappa_{\text {ele }}$ was $0.68-1 \mathrm{~W} \mathrm{~m}^{-1} \mathrm{k}^{-1}$ for the undoped $\mathrm{Cu}_{2} \mathrm{Se}$, and it decreased to 0.27 $0.39 \mathrm{~W} \mathrm{~m}^{-1} \mathrm{~K}^{-1}$ for the $0.42 \mathrm{wt} \%$ boron doped $\mathrm{Cu}_{2} \mathrm{Se}$. The dependence of $\kappa_{\text {lat }}$ of all samples on temperature is shown in Fig. 7c. The $\kappa_{\text {lat }}$ value is significantly lower than for most the 
reported polycrystalline samples at $0.23 \mathrm{~W} \mathrm{~m}^{-1} \mathrm{~K}^{-1},{ }^{12,28,34-36}$ as shown in Fig. 7c and d. The reduced transmission of heat is most obviously correlated with extremely low $\kappa_{\text {lat }}$ along with $\kappa_{\text {ele }}$ and is due to the decreased number of charge carriers as well as the lattice vibrations through the complex heterogeneous microstructure of our boron doped polycrystalline $\mathrm{Cu}_{2} \mathrm{Se}$ with boron nano-inclusions at the grain boundaries. The $\kappa_{L}$ of a polycrystalline solid can be determined using the following relation ${ }^{37}$ :

$$
\kappa_{p}^{-1}=\kappa_{b}^{-1}+\frac{R_{\kappa}}{d}
$$

Where, $\kappa_{b}, \kappa_{p}, 1 / \bar{d}$ and $R_{\kappa}$ are the intrinsic thermal conductivity of $\mathrm{Cu}_{2} \mathrm{Se}$, the change in thermal conductivity of a doped sample, the inverse average grain size, and the grain boundary resistance, respectively. The reduction of transmission of heat observed using this model is due to the thermal resistance developed across the interface, and it becomes more strengthened as the number of interfaces increase in microcrystalline solids. The key parameter $R_{\mathrm{K}}$ represented the percentage of grain boundary covered by the boron inclusions and the reflection of phonons instead of transport through the edge of the grain. A negligible $R_{\kappa}$ value of $\sim 1 \times 10^{-9} \mathrm{~m}^{2} \cdot \mathrm{K} \cdot \mathrm{W}^{-1}$ is found in the intrinsic $\mathrm{Cu}_{2} \mathrm{Se}$ solid due to the large crystalline grain size, while micro- and nanograins have almost the same $\kappa_{p},{ }^{20}$ whereas it becomes significant with the boron inclusions near the edge, in conformity with other thermoelectric results, ${ }^{37}$ The average grain size of the boron doped sample was found to be $0.4 \mu \mathrm{m}$ with $\kappa_{b}$ and $\kappa_{p}$ of $1.41 \mathrm{~W} \cdot \mathrm{m}^{-1} \cdot \mathrm{K}^{-1}$ and $0.73 \mathrm{~W} \cdot \mathrm{m}^{-1} \cdot \mathrm{K}^{-1}$, respectively, which results in the ultra-high $R_{\kappa}$ value $2.63 \times 10^{-7} \mathrm{~m}^{2} \cdot \mathrm{K} \cdot \mathrm{W}^{-1}$. This value is comparable to the results for recently reported graphene doped thermoelectric materials. ${ }^{37}$

Thermoelectric materials with good mechanical properties can better sustain strong mechanical and thermal stresses and improve the reliability of segmented thermoelectric modules. ${ }^{38-40}$ Fig. 8 shows the microhardness values of the pure $\mathrm{Cu}_{2} \mathrm{Se}$ and boron doped 
$\mathrm{Cu}_{2} \mathrm{Se}$ bulks. The hardness value of the pure $\mathrm{Cu}_{2} \mathrm{Se}$ bulk is found to be $\sim 0.38 \mathrm{GPa}$, and this mechanical performance gradually increases with increasing content of boron. The measured hardness values are $0.40,0.43$, and $0.45 \mathrm{GPa}$ for the $0.14 \mathrm{wt} \% \mathrm{~B}, 0.28 \mathrm{wt} \% \mathrm{~B}$, and $0.42 \mathrm{wt} \%$ $\mathrm{B}$ doped $\mathrm{Cu}_{2} \mathrm{Se}$ samples, respectively. These values are comparable to those for reported polycrystalline $\mathrm{Cu}_{2} \mathrm{Se}$ solids ( $\left.\sim .40 \mathrm{GPa}\right)$ prepared using melt-quenching approach. ${ }^{13}$

\section{Conclusions}

We have demonstrated that nano-boron particles can significantly enhance the $z T$ of $\mathrm{Cu}_{2} \mathrm{Se}$. Our studies indicate that boron inclusion can considerably reduce the thermal conductivity, while preserving high power factor, resulting in enhancement of $z T$ by a factor of 1.6-2.6 over a wide temperature range compared to undoped samples. The mechanism for this improvement of $z T$ is that the reduction of heat conduction by boron-decorated microstructure edges increases the boundary resistance with decreasing carrier concentration. Our findings offer an effective approach of using insulating nano-particles to achieve high $z T$ in $\mathrm{Cu}_{2} \mathrm{Se}$ and many other types of thermoelectric composites.

\section{Experimental}

\section{Synthesis}

Firstly, the polycrystalline $\mathrm{Cu}_{2} \mathrm{Se}$ powders were milled in a high energy ball-mill to mix with amorphous boron (B) powders. The balls to powder weight ratio was $10: 1$. The rotation conditions were set to $500 \mathrm{rpm}$ for 4 hours. The weight ratios of $\mathrm{Cu}_{2} \mathrm{Se}$ and $\mathrm{B}$ are 1: $x(x=$ $0.14 \%, 0.28 \%$, and $0.42 \%$ ). The highly dense $20 \mathrm{~mm}$ diameter and $2 \mathrm{~mm}$ thick solids were formed by spark plasma sintering (SPS; Thermal Technology SPS model 10-4) at $773 \mathrm{~K}$ for just 10 min under a pressure of $40 \mathrm{MPa}$ in vacuum. Finally, the samples were shaped into a rectangular bar and round disks using a cutting machine (Struers Accutom-50) for electrical and thermal transport measurements, respectively. The boron-doped $\mathrm{Cu}_{2} \mathrm{Se}$ samples are 
denoted by their boron weight percent, so that the sample with $0.14 \mathrm{wt} \%$ boron was denoted as $0.14 \mathrm{~B}$, etc.

\section{Measurement summary}

The room temperature powder diffraction patterns were determined by X-ray diffractometry $\left(\mathrm{Cu} \mathrm{K} \alpha, \mathrm{GBC}\right.$ MMA) $(\lambda=1.5418 \AA), 10^{\circ} \leq 2 \theta \leq 60^{\circ}$, in step scan mode with a step size of $0.014^{\circ}$ and speed of 1 degree per min. The Australian Synchrotron was used to collect high resolution data using a wavelength of $\lambda=0.58973 \AA$, where the detectors covered an angular range of $2.5^{\circ} \leq 2 \theta \leq 80^{\circ}$, simultaneously every 30 seconds and the sample was rotated at $\sim 1$ $\mathrm{Hz}$ with a heating rate of $4 \mathrm{deg} . / \mathrm{min}$ under helium gas flow over the 300-774 K temperature range. The sample morphologies and microstructures were investigated with field emission scanning electron microscopy (FE-SEM, JEOL 7500), and transmission electron microscopy (TEM, JEOL ARM200F) was used to investigate the phase composition and microstructure of the undoped and boron doped $\mathrm{Cu}_{2} \mathrm{Se}$ samples. The thin TEM specimens were prepared using focused ion beam milling (FIB, FEI Helios Nanolab) after being mounted in Polyfast ${ }^{\circledR}$ using Struers Citopress-20 equipment and polished with Struers Tegramin-20 water equipment, before they were used for scanning transmission electron microscopy/X-ray spectroscopy (STEM/X-ray mapping) investigations. Room temperature Hall coefficient measurements were performed to determine the carrier concentration and carrier mobility using a physical properties measurement system (Quantum Design PPMS-9). The $\sigma$ and $S$ were simultaneously measured from room temperature to $852 \mathrm{~K}$ under vacuum using a commercial RZ2001i system. The laser flash method (LINSEIS LFA 1000) was used to measure thermal diffusivity under vacuum conditions. The heat capacity $\left(C_{\mathrm{p}}\right)$ was measured by differential scanning calorimetry (DSC-204F1 Phoenix) under argon atmosphere. The weight and dimensions were used to measure the sample density $(d d)$ and found 6.480, 6.375, 6.255 , and $6.161 \mathrm{~g} / \mathrm{cm}^{3}$ for the undoped, $0.14,0.28$ and $0.42 \mathrm{~B}$. The total thermal conductivity 
( $\kappa$ ) was calculated using the formula $\kappa=D \times C_{\mathrm{p}} \times d d$. The Vickers Hardness measurements of the undoped and boron doped $\mathrm{Cu}_{2} \mathrm{Se}$ samples were carried out under $0.245 \mathrm{~N}$ load in Lens (60x) using Struers Emco-Test DuraScan-70. All the transport measurements were repeated several times to check the consistency of the polycrystalline samples.

\section{Conflicts of interest}

There are no conflicts to declare.

\section{Acknowledgements}

This work was partially supported by the Australian Research Council (ARC) through a Discovery Project DP 130102956 (XLW), an ARC Professorial Future Fellowship project (FT 130100778, XLW), and a Linkage Infrastructure Equipment and Facilities (LIEF) Grant (LE 120100069, XLW). This research also used equipment funded by the Australian Research Council (ARC) FEI NanoLab G3 CX: LE160100063 and ARM- LE120100104. We are thankful to Mitchell Nancarrow, David Cortie and Michael Cortie for assistance with sample preparations for SEM/TEM analysis and Synchrotron experiments. 


\section{Figures and Captions:}

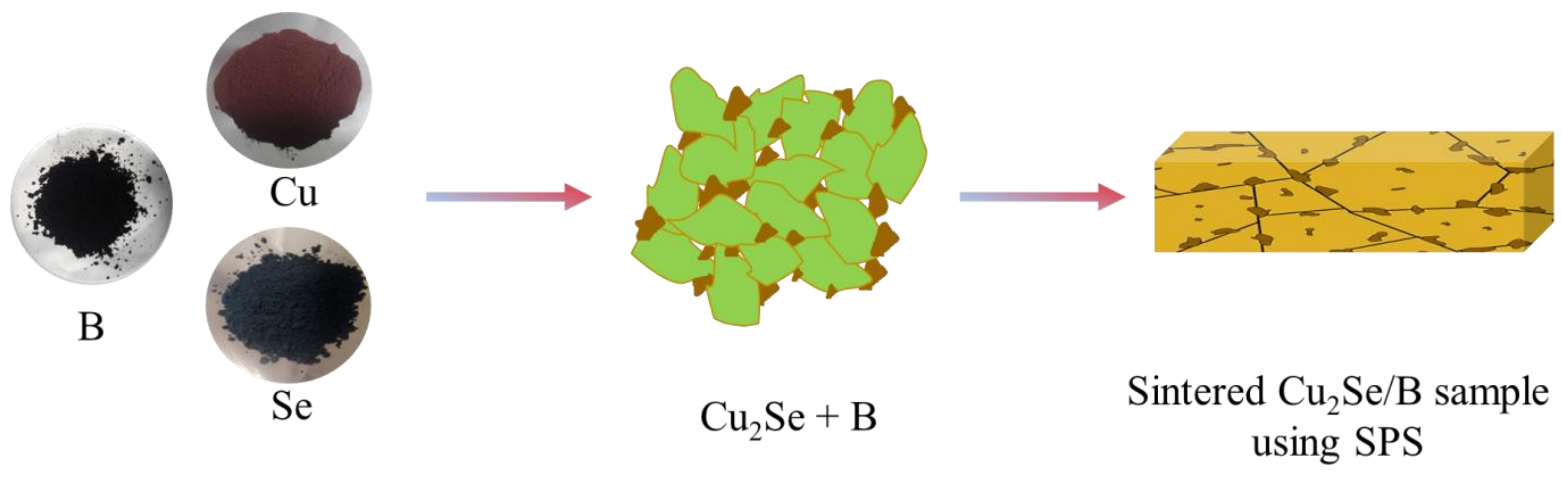

Fig. 1 Schematic illustration showing the formation mechanism of the B-doped $\mathrm{Cu}_{2} \mathrm{Se}$ bulks with the fabrication process. 

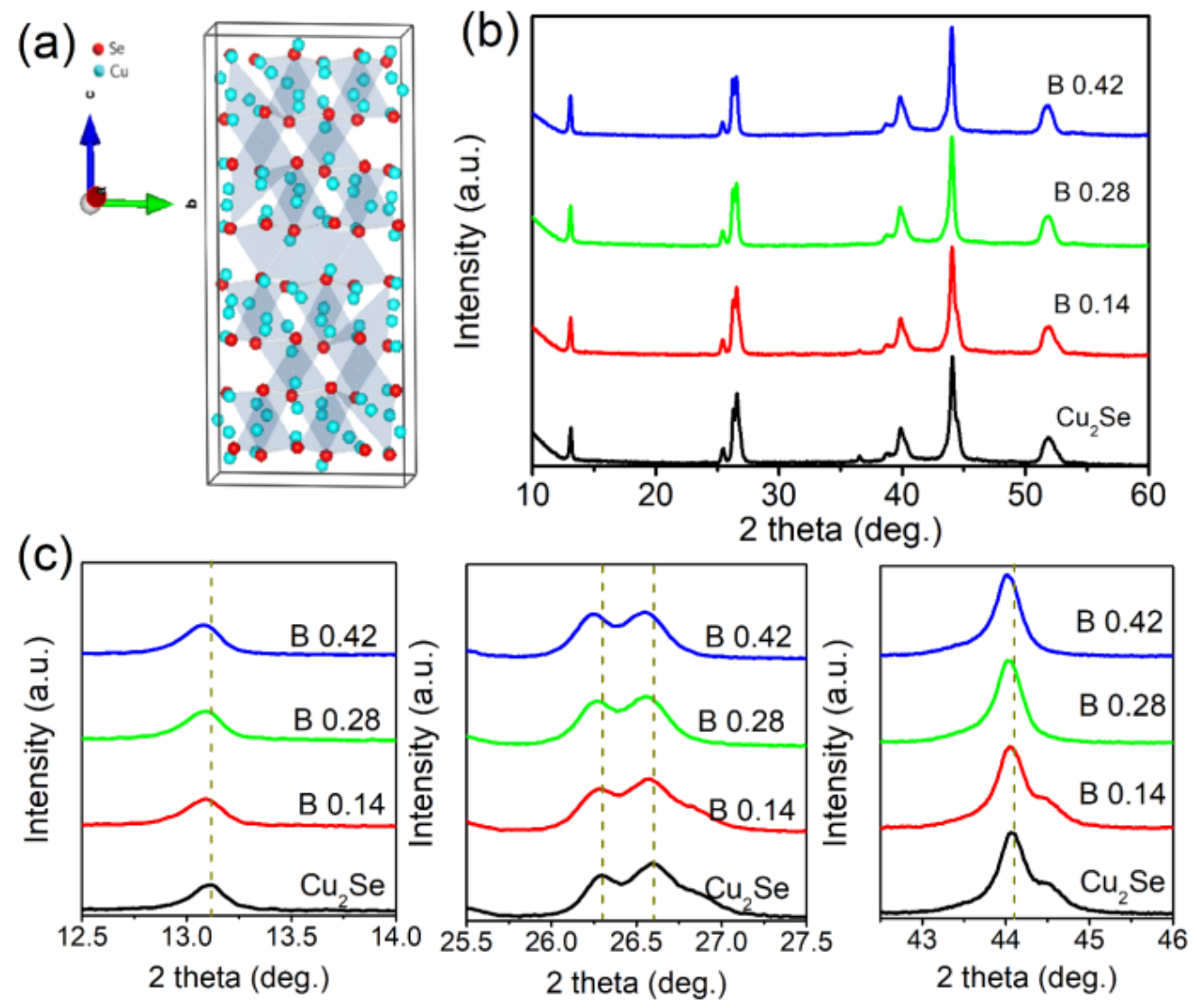

Fig. 2 (a) Schematic illustration of the crystal structure of $\alpha$-phase $\mathrm{Cu}_{2} \mathrm{Se}$, and (b) $\mathrm{X}$-ray diffraction patterns of pure $\mathrm{Cu}_{2} \mathrm{Se}$ and boron doped $\mathrm{Cu}_{2} \mathrm{Se}\left(\mathrm{Cu}_{2} \mathrm{Se}-x \mathrm{wt} \% \mathrm{~B}\right.$ samples $(x=0$, $0.14,0.28$, and 0.42 )) showing that the peak intensity at $37 \mathrm{deg}$ 2-theta disappears at high $\mathrm{B}$ contents, (c) enlarged peaks for the undoped and boron doped $\mathrm{Cu}_{2} \mathrm{Se}$ samples showing that all the peaks shift to the left with boron doping and one peak in the right (c) disappears with the boron. 

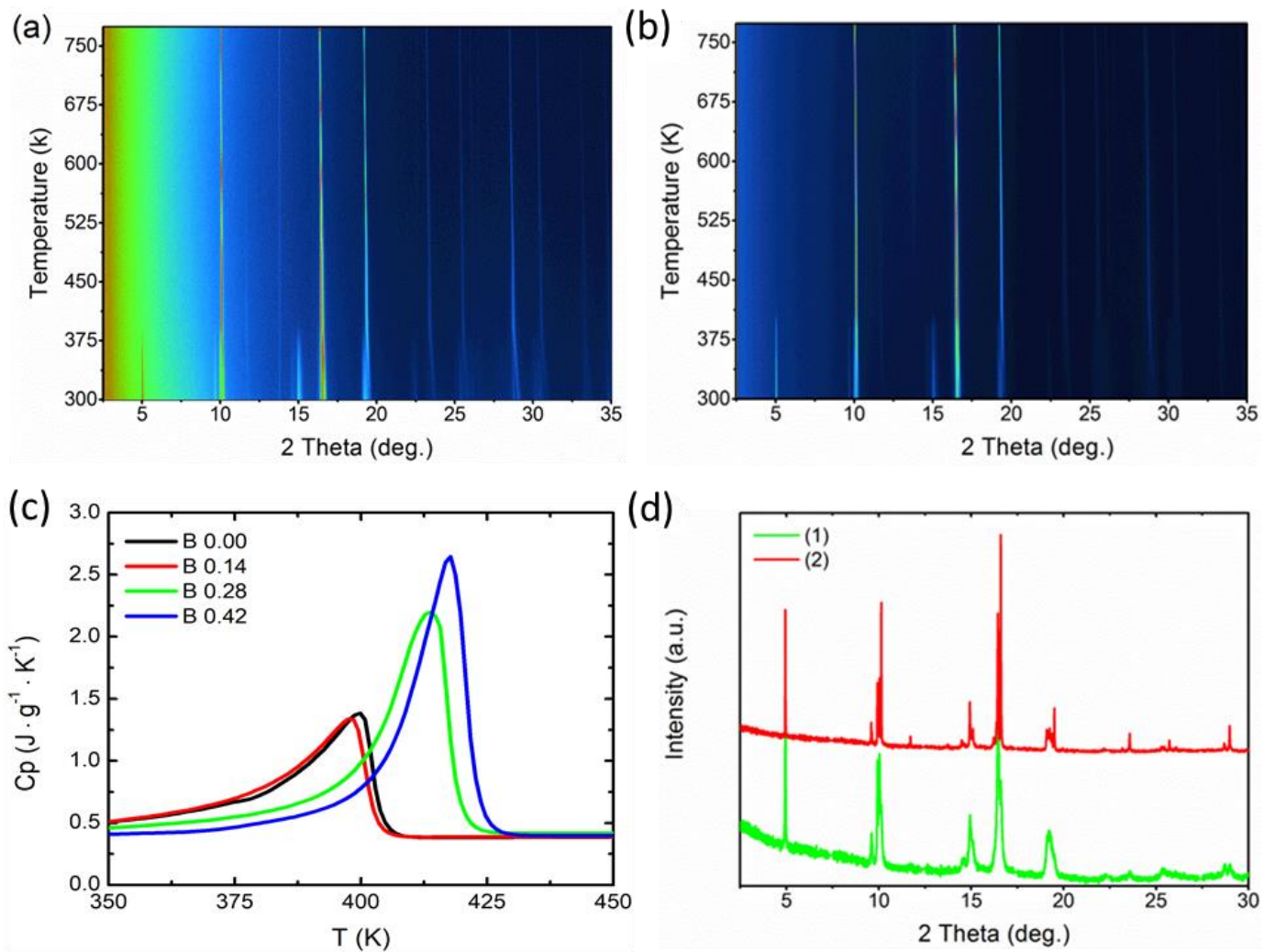

Fig. 3 Synchrotron radiation X-ray diffraction (SR-XRD) profiles of (a) pure $\mathrm{Cu}_{2} \mathrm{Se}$ and (b) 0.42 wt $\%$ boron doped $\mathrm{Cu}_{2} \mathrm{Se}$ obtained upon heating to different temperatures; (c) Temperature dependence of the heat capacity $\left(C_{\mathrm{p}}\right)$ for the undoped and boron doped $\mathrm{Cu}_{2} \mathrm{Se}$ samples; (d) XRD patterns for $\mathrm{Cu}_{2} \mathrm{Se} / 0.42 \mathrm{wt} \%$ boron obtained at $300 \mathrm{~K}$ at the beginning of the measurement (1) and after the measurement (2), respectively. 
(a)
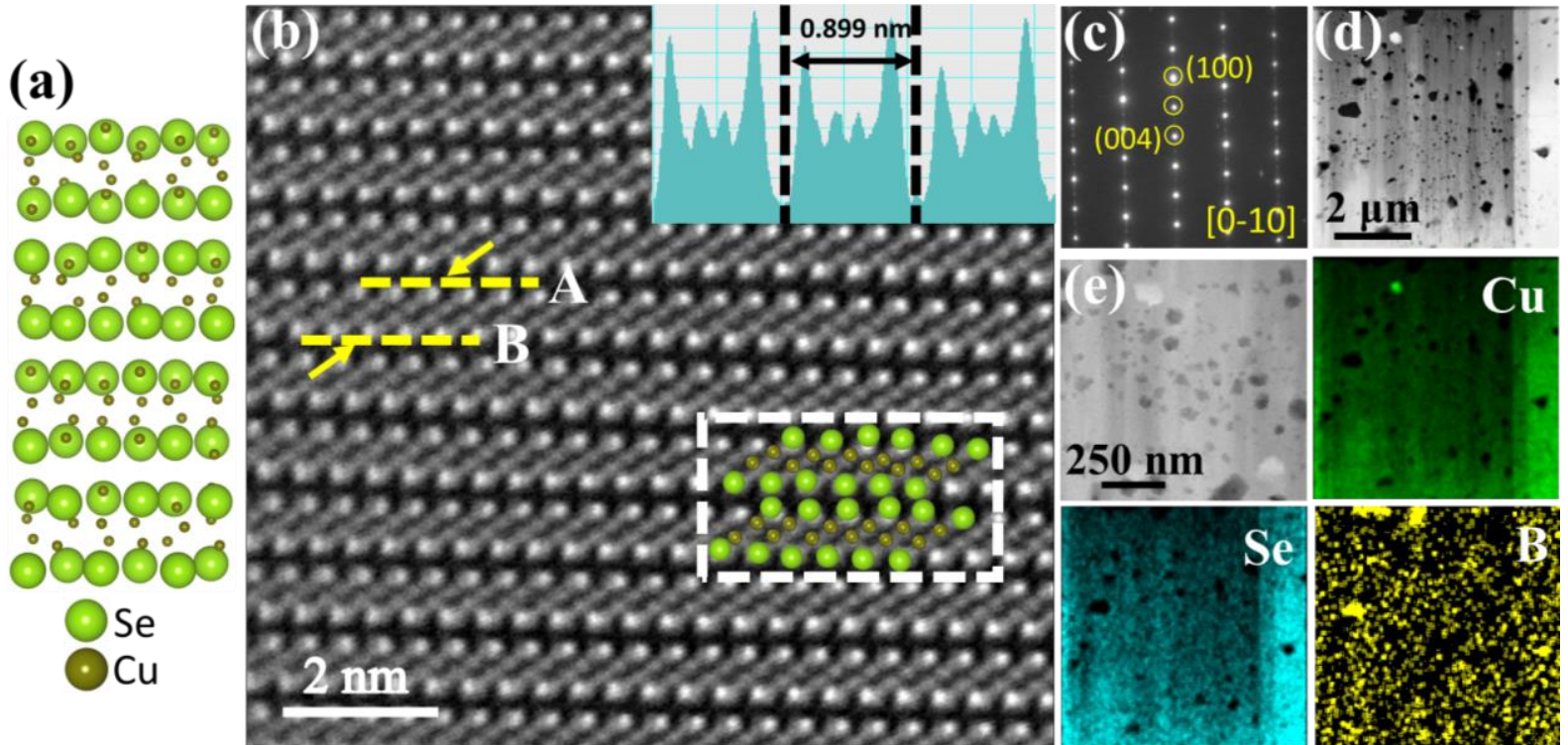

$\mathrm{Cu}$

Fig. 4 Structural characterization of 0.42 wt $\%$ boron-doped $\mathrm{Cu}_{2} \mathrm{Se}$ polycrystals. (a) Ball model of the monoclinic unit cell of $\mathrm{Cu}_{2} \mathrm{Se}$ representing the dashed square of the main panel of (b). (b) Atomic resolution HAADF image at room temperature along the [0 - 10$]$ zone axis, where the $\mathrm{Se}$ atoms are represented by the yellow balls and the weak contrast $\mathrm{Cu}$ atoms among Se layers are represented by the red balls in the bottom inset; Top inset: the line profile along the dotted line $\mathrm{AB}$ in the main panel, showing the spacing between two Se. (c) The SAED pattern along the $\left[\begin{array}{lll}0 & -1 & 0\end{array}\right]$ orientation. (d) HAADF STEM image of the FIB milled sample, showing boron-rich precipitates within the $\mathrm{Cu}_{2} \mathrm{Se}$-rich matrix along with the corresponding EDS elemental mapping for $\mathrm{Cu}$, Se and B. Average Boron particle sizes are 80 nm. (e) Magnified observation of boron-rich precipitates within the $\mathrm{Cu}_{2} \mathrm{Se}$-rich matrix. 
(a)

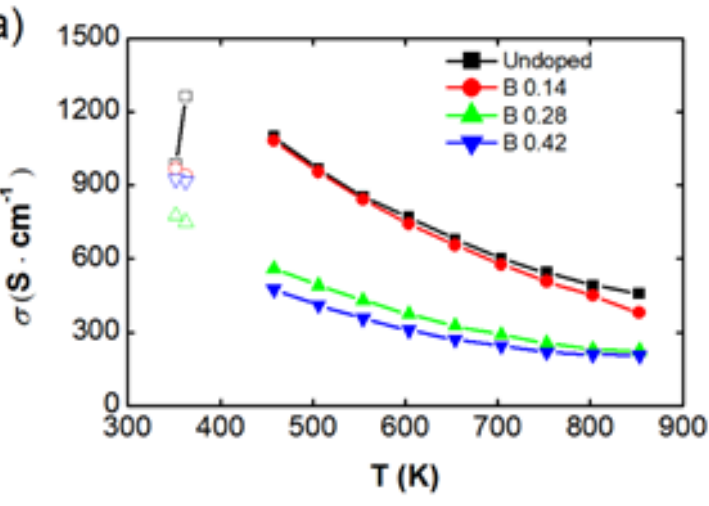

(c)

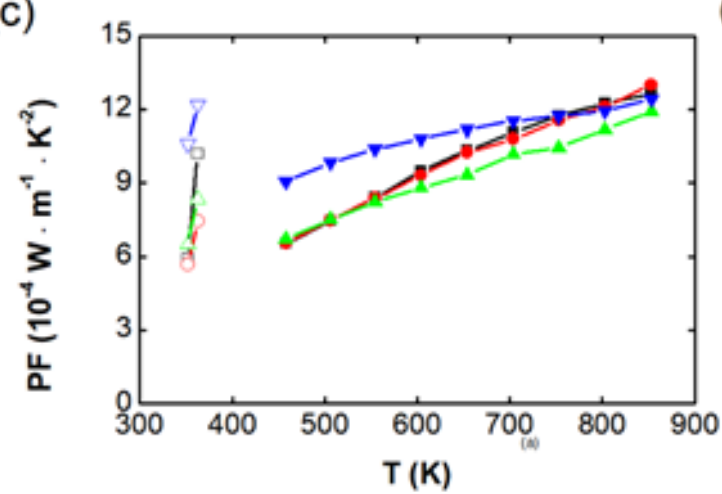

(e)

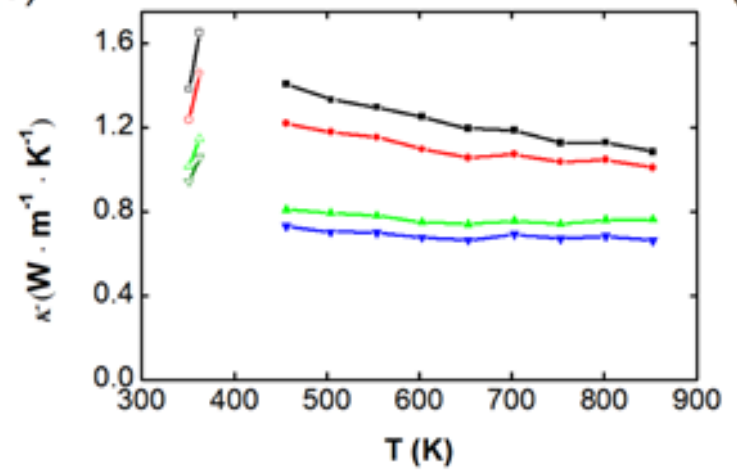

(b)

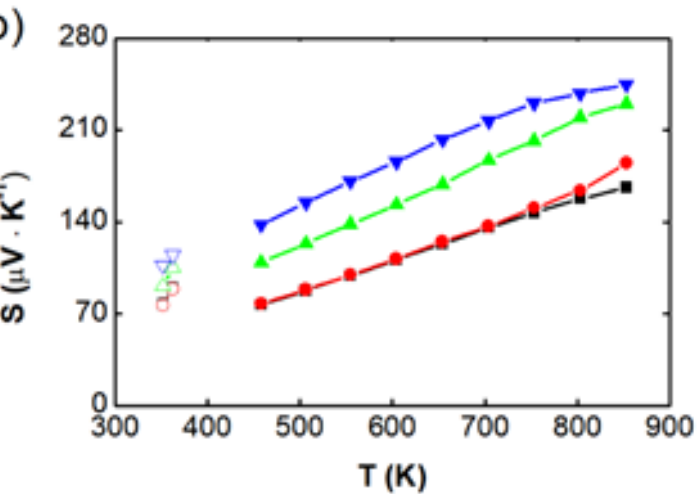

(d)

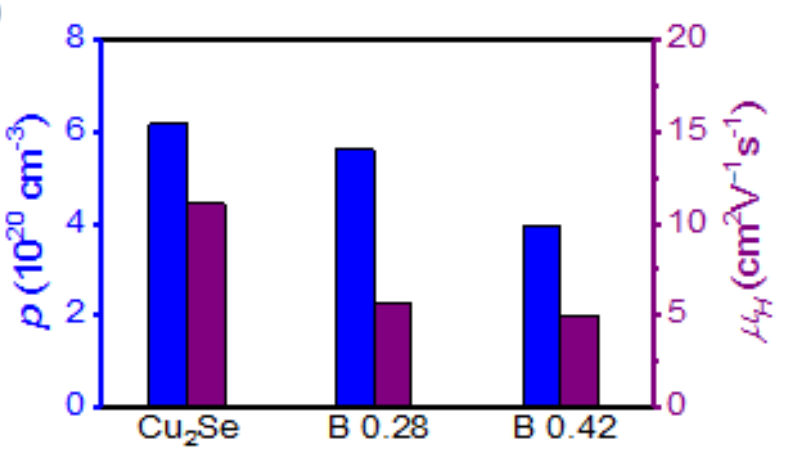

(f)

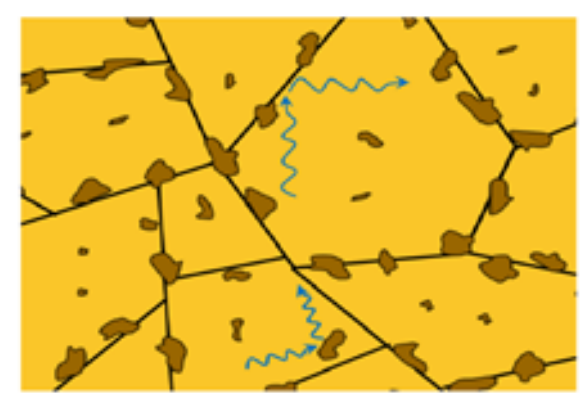

Fig. 5 Temperature dependence of the thermoelectric transport properties of the samples: (a) electrical conductivity $(\sigma)$, (b) Seebeck coefficient $(S)$, (c) Power factor (PF); (d) Carrier concentration and carrier mobility for the pure, $0.28 \mathrm{wt} \%$ boron and $0.42 \mathrm{wt} \%$ boron doped $\mathrm{Cu}_{2} \mathrm{Se}$ samples; (e) Thermal conductivity $(\kappa)$ as a function of temperature; and (f) Schematic diagram of $\mathrm{B}$-doped $\mathrm{Cu}_{2} \mathrm{Se}$ composite, showing the microstructure and phonon transportation. 
(a)

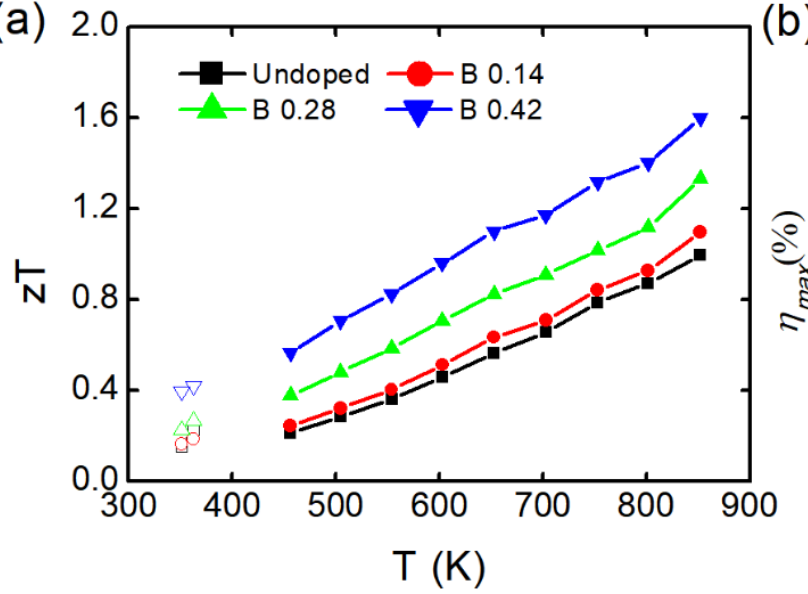

(b)

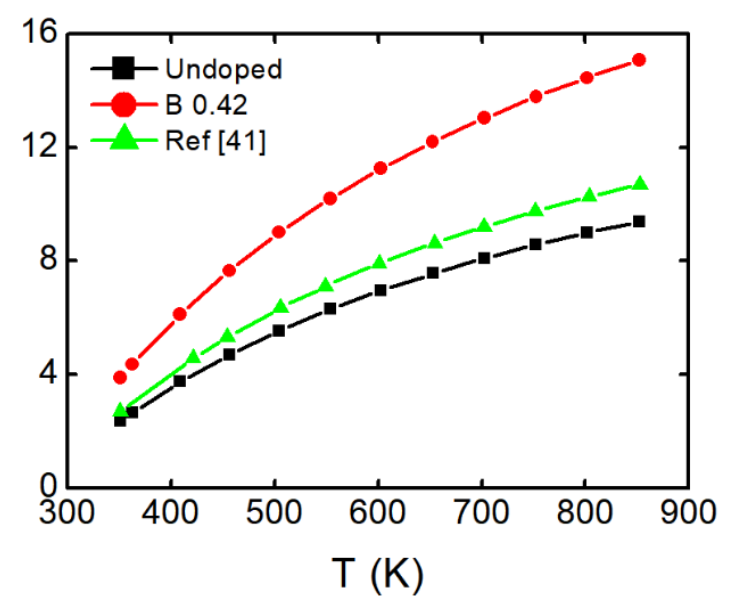

Fig. 6 Thermoelectric figure of merit $z T$ for the undoped and B-doped $\mathrm{Cu}_{2} \mathrm{Se}$ with different wt $\%$ B. b) Thermoelectric efficiency of the undoped and B-doped $\mathrm{Cu}_{2} \mathrm{Se}$ samples, in comparison with the previously reported $\mathrm{Cu}_{2} \mathrm{Se}$ data. ${ }^{41}$ 
(a)
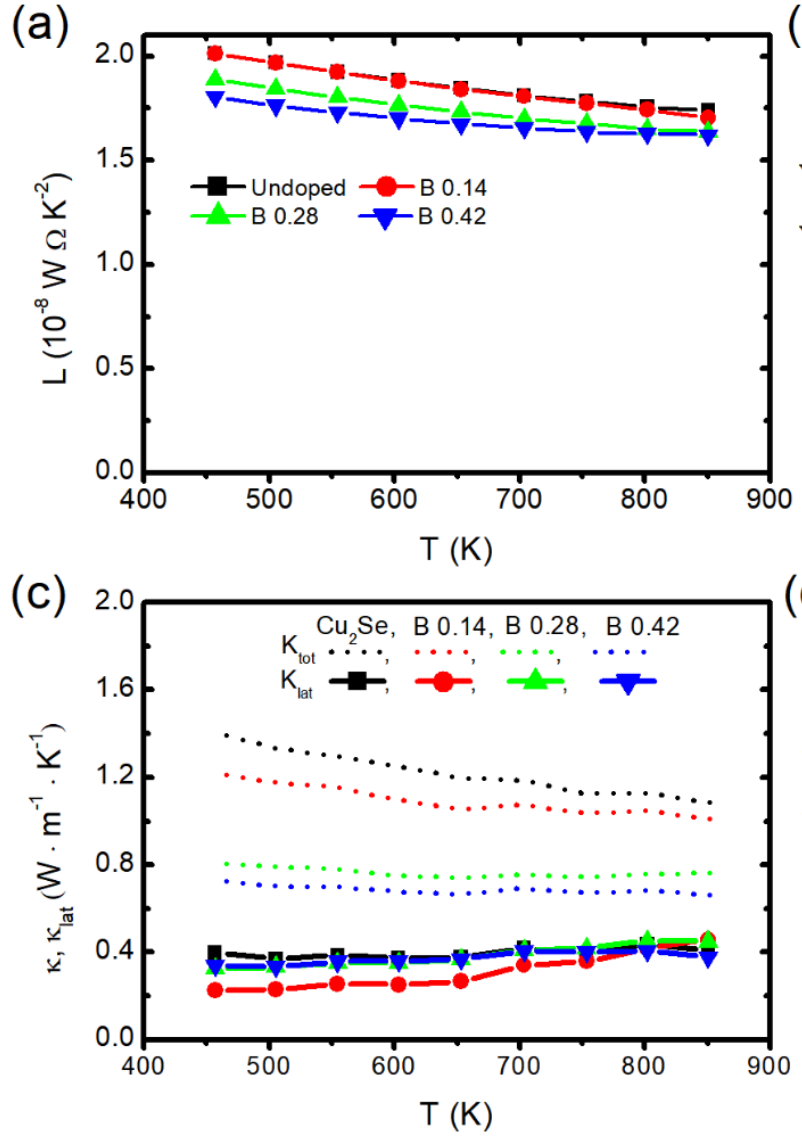

(b)

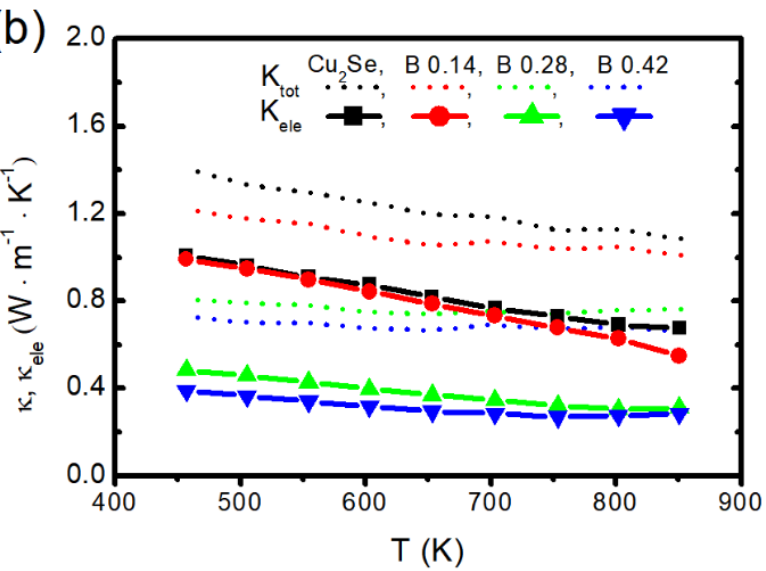

(d)

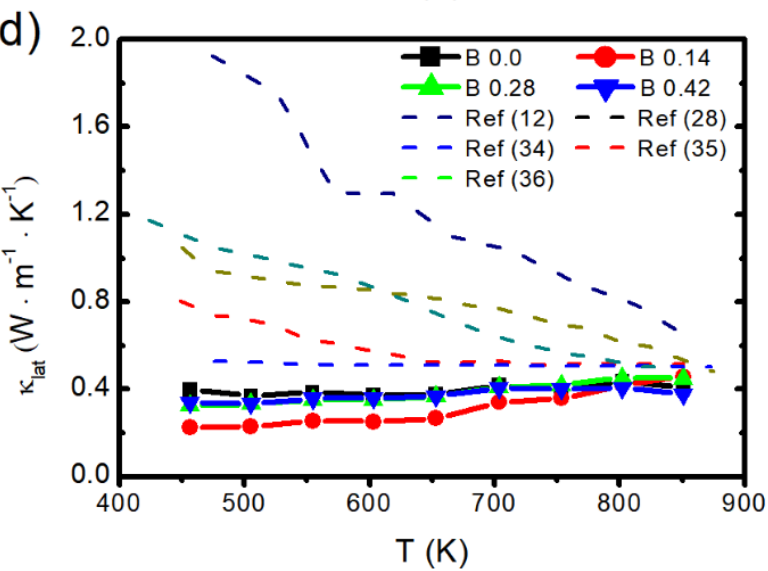

Fig. 7 Temperature dependence of the thermal transport properties for the undoped and boron doped polycrystalline samples: (a) The calculated Lorenz number $(L)$ of undoped and boron doped $\mathrm{Cu}_{2} \mathrm{Se}$.; (b) total thermal conductivity $(\kappa)$ and electronic thermal conductivity $\left(\kappa_{C}\right)$; (c) lattice thermal conductivity $\left(\kappa_{L}\right)$ with total thermal conductivity $(\kappa)$; $(d)$ comparison of the boron doped $\kappa_{\text {lat }}$ values and $\kappa_{\text {tot }}$ values (dotted lines with those of state-of-the-art $\mathrm{Cu}_{2} \mathrm{Se},{ }^{12,}{ }^{28}$, ${ }^{34} \mathrm{PbTeSe},{ }^{35} \mathrm{PbTe},{ }^{36}$ polycrystals. 


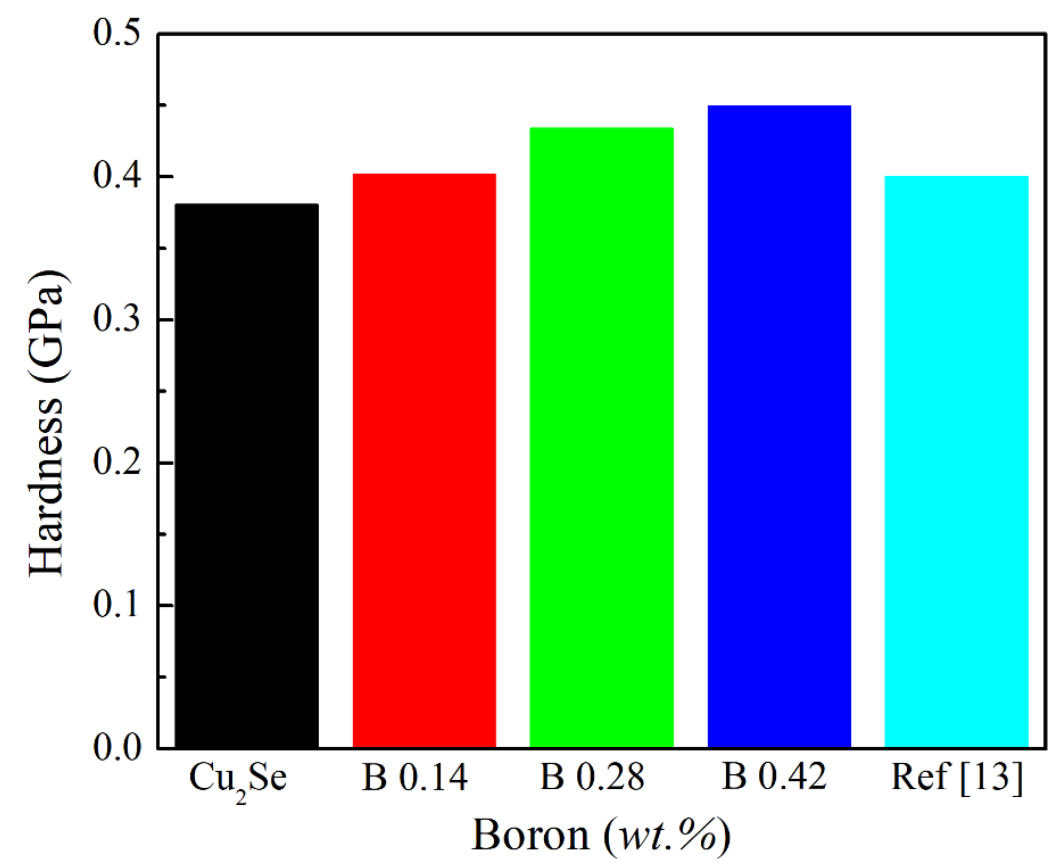

Fig. 8 Hardness of the undoped and boron doped $\mathrm{Cu}_{2} \mathrm{Se}$ polycrystalline samples in comparison with data for $\mathrm{Cu}_{2} \mathrm{Se}$ polycrystalline bulks. ${ }^{13}$ 


\section{References}

1. F. J. DiSalvo, Science, 1999, 285, 703-706.

2. L. E. Bell, Science, 2008, 321, 1457-1461.

3. A. I. Hochbaum, R. Chen, R. D. Delgado, W. Liang, E. C. Garnett, M. Najarian, A. Majumdar and P. Yang, Nature, 2008, 451, 163-167.

4. J. P. Heremans, V. Jovovic, E. S. Toberer, A. Saramat, K. Kurosaki, A. Charoenphakdee, S. Yamanaka and G. J. Snyder, Science, 2008, 321, 554-557.

5. T. Caillat, J.-P. Fleurial and A. Borshchevsky, Journal of Physics and Chemistry of Solids, 1997, 58, 1119-1125.

6. Y. Du, K. Cai, S. Chen, H. Wang, S. Z. Shen, R. Donelson and T. Lin, Scientific reports, 2015, 5, 6411.

7. Y. W. Tung and M. L. Cohen, Physical Review, 1969, 180, 823-826.

8. S. D. Kang, J.-H. Pöhls, U. Aydemir, P. Qiu, C. C. Stoumpos, R. Hanus, M. A. White, X. Shi, L. Chen and M. G. Kanatzidis, Materials Today Physics, 2017, 1, 7-13.

9. A. Suzumura, M. Watanabe, N. Nagasako and R. Asahi, Journal of Electronic Materials, 2014, 43, 2356-2361.

10. B. Zhong, Y. Zhang, W. Li, Z. Chen, J. Cui, W. Li, Y. Xie, Q. Hao and Q. He, Applied Physics Letters, 2014, 105, 123902.

11. J. Fan, W. Carrillo-Cabrera, I. Antonyshyn, Y. Prots, I. Veremchuk, W. Schnelle, C. Drathen, L. Chen and Y. Grin, Chemistry of Materials, 2014, 26, 5244-5251.

12. S. Ballikaya, H. Chi, J. R. Salvador and C. Uher, Journal of Materials Chemistry A, 2013, 1, 12478-12484.

13. L. Zhao, X. Wang, F. F. Yun, J. Wang, Z. Cheng, S. Dou, J. Wang and G. J. Snyder, Advanced Electronic Materials, 2015, 1, 1400015.

14. L. Zhao, F. Y. Fei, J. Wang, F. Wang, C. Wang, J. Li, J. Wang, Z. Cheng, S. Dou and X. Wang, Scientific Reports, 2017, 7, 40436.

15. H. Liu, X. Yuan, P. Lu, X. Shi, F. Xu, Y. He, Y. Tang, S. Bai, W. Zhang and L. Chen, Advanced Materials, 2013, 25, 6607-6612.

16. T. W. Day, K. S. Weldert, W. G. Zeier, B.-R. Chen, S. L. Moffitt, U. Weis, K. P. Jochum, M. Panthöfer, M. J. Bedzyk, G. J. Snyder and W. Tremel, Chemistry of Materials, 2015, 27, 7018-7027.

17. L. Zhao, S. M. K. N. Islam, J. Wang, D. L. Cortie, X. Wang, Z. Cheng, J. Wang, N. Ye, S. Dou, X. Shi, L. Chen, G. J. Snyder and X. Wang, Nano Energy, 2017, 41, 164171.

18. R. Nunna, P. Qiu, M. Yin, H. Chen, R. Hanus, Q. Song, T. Zhang, M.-Y. Chou, M. T. Agne and J. He, Energy \& Environmental Science, 2017, 10, 1928-1935.

19. M. Li, S. M. Kazi Nazrul Islam, S. Dou and X. Wang, Journal of Alloys and Compounds, 2018, 769, 59-64.

20. L.-1. Zhao, X.-1. Wang, J.-y. Wang, Z.-x. Cheng, S.-x. Dou, J. Wang and L.-q. Liu, Scientific reports, 2015, 5, 7671.

21. T. Mori, Material Matters, 2009, 4, 37-39.

22. D. A. Atwood, The rare earth elements: fundamentals and applications, John Wiley \& Sons, 2013. 
23. T. Mori, J. Martin and G. Nolas, Journal of Applied Physics, 2007, 102, 073510.

24. D. G. Cahill, H. E. Fischer, S. Watson, R. Pohl and G. Slack, Physical Review B, 1989, 40, 3254.

25. E. Ekimov, V. Sidorov, E. Bauer, N. Mel'Nik, N. Curro, J. Thompson and S. Stishov, nature, 2004, 428, 542.

26. A. R. Oganov, J. Chen, C. Gatti, Y. Ma, Y. Ma, C. W. Glass, Z. Liu, T. Yu, O. O. Kurakevych and V. L. Solozhenko, Nature, 2009, 457, 863.

27. U. Aydemir, J.-H. Pöhls, H. Zhu, G. Hautier, S. Bajaj, Z. M. Gibbs, W. Chen, G. Li, S. Ohno and D. Broberg, Journal of Materials Chemistry A, 2016, 4, 2461-2472.

28. B. Yu, W. Liu, S. Chen, H. Wang, H. Wang, G. Chen and Z. Ren, Nano Energy, 2012, 1, 472-478.

29. Y.-B. Zhu, B.-P. Zhang and Y. Liu, Physical Chemistry Chemical Physics, 2017, 19, 27664-27669.

30. D. Li, X. Y. Qin, Y. F. Liu, C. J. Song, L. Wang, J. Zhang, H. X. Xin, G. L. Guo, T. H. Zou and G. L. Sun, Rsc Advances, 2014, 4, 8638-8644.

31. H. S. Kim, W. Liu, G. Chen, C.-W. Chu and Z. Ren, Proceedings of the National Academy of Sciences, 2015, 112, 8205-8210.

32. H.-S. Kim, Z. M. Gibbs, Y. Tang, H. Wang and G. J. Snyder, APL materials, 2015, 3, 041506.

33. R. J. Mehta, Y. Zhang, C. Karthik, B. Singh, R. W. Siegel, T. Borca-Tasciuc and G. Ramanath, Nature materials, 2012, 11, 233.

34. B. Gahtori, S. Bathula, K. Tyagi, M. Jayasimhadri, A. Srivastava, S. Singh, R. Budhani and A. Dhar, Nano Energy, 2015, 13, 36-46.

35. Y. Pei, X. Shi, A. LaLonde, H. Wang, L. Chen and G. J. Snyder, Nature, 2011, 473, 66-69.

36. K. Biswas, J. He, I. D. Blum, C.-I. Wu, T. P. Hogan, D. N. Seidman, V. P. Dravid and M. G. Kanatzidis, Nature, 2012, 489, 414-418.

37. P.-a. Zong, R. Hanus, M. Dylla, Y. Tang, J. Liao, Q. Zhang, G. J. Snyder and L. Chen, Energy \& Environmental Science, 2017, 10, 183-191.

38. K. Ueno, A. Yamamoto, T. Noguchi, T. Inoue, S. Sodeoka and H. Obara, Journal of alloys and compounds, 2005, 388, 118-121.

39. F. Ren, H. Wang, P. A. Menchhofer and J. O. Kiggans, Applied Physics Letters, 2013, 103, 221907.

40. J. E. Ni, E. D. Case, K. N. Khabir, R. C. Stewart, C.-I. Wu, T. P. Hogan, E. J. Timm, S. N. Girard and M. G. Kanatzidis, Materials Science and Engineering: B, 2010, 170, 58-66.

41. H. Liu, X. Shi, F. Xu, L. Zhang, W. Zhang, L. Chen, Q. Li, C. Uher, T. Day and G. J. Snyder, Nature Materials, 2012, 11, 422.

\section{Footnote}

$\dagger$ Electronic supplementary information (ESI) available: figures, table 


\section{Supporting Information}

\section{Giant enhancement of the figure-of-merit over a broad temperature range in nano-boron incorporated $\mathrm{Cu}_{2} \mathrm{Se}$}

Sheik Md. Kazi Nazrul Islam ${ }^{\text {a }}$, Meng Li ${ }^{\text {a }}$, Umut Aydemir ${ }^{\text {c }}$, Xun Shi ${ }^{\mathrm{d}}$, Lidong Chen ${ }^{\mathrm{d}}$, G Jeffrey Snyder ${ }^{\mathrm{e}}$, and Xiaolin Wang ${ }^{* a b}$

* Corresponding authors

${ }^{a}$ Institute for Superconducting and Electronic Materials, Australian Institute for Innovative Materials, University of Wollongong, North Wollongong, NSW 2500, Australia, E-mail: xiaolin@uow.edu.au

${ }^{\mathrm{b}}$ ARC Centre of Excellence in Future Low-Energy Electronics Technologies, University of Wollongong, Australia

${ }^{c}$ Department of Chemistry, Koc University, Sariyer, Istanbul, 34450, Turkey

d State Key Laboratory of High Performance Ceramics and Superfine Microstructures, Shanghai Institute of Ceramics, Chinese Academy of Sciences, 1295 Dingxi Road, Shanghai, China, 200050

e Northwestern University, 2220 Campus Drive, Cook Hall, Evanston, IL 60208-3109, USA

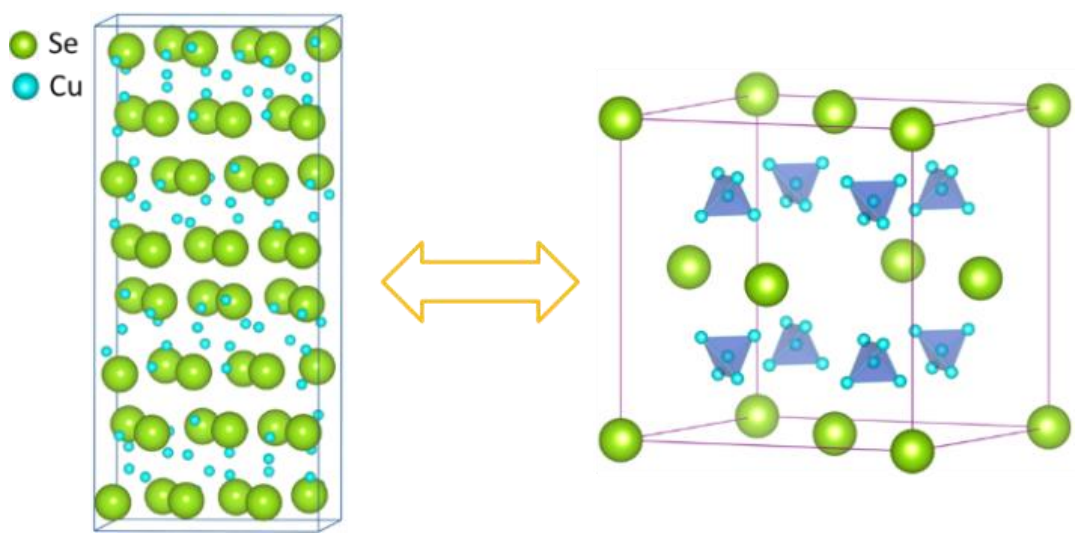

Fig. S1 Low-temperature monoclinic phase (left) and high-temperature cubic phase (right) of the $\mathrm{Cu}_{2} \mathrm{Se}$ crystal structure 

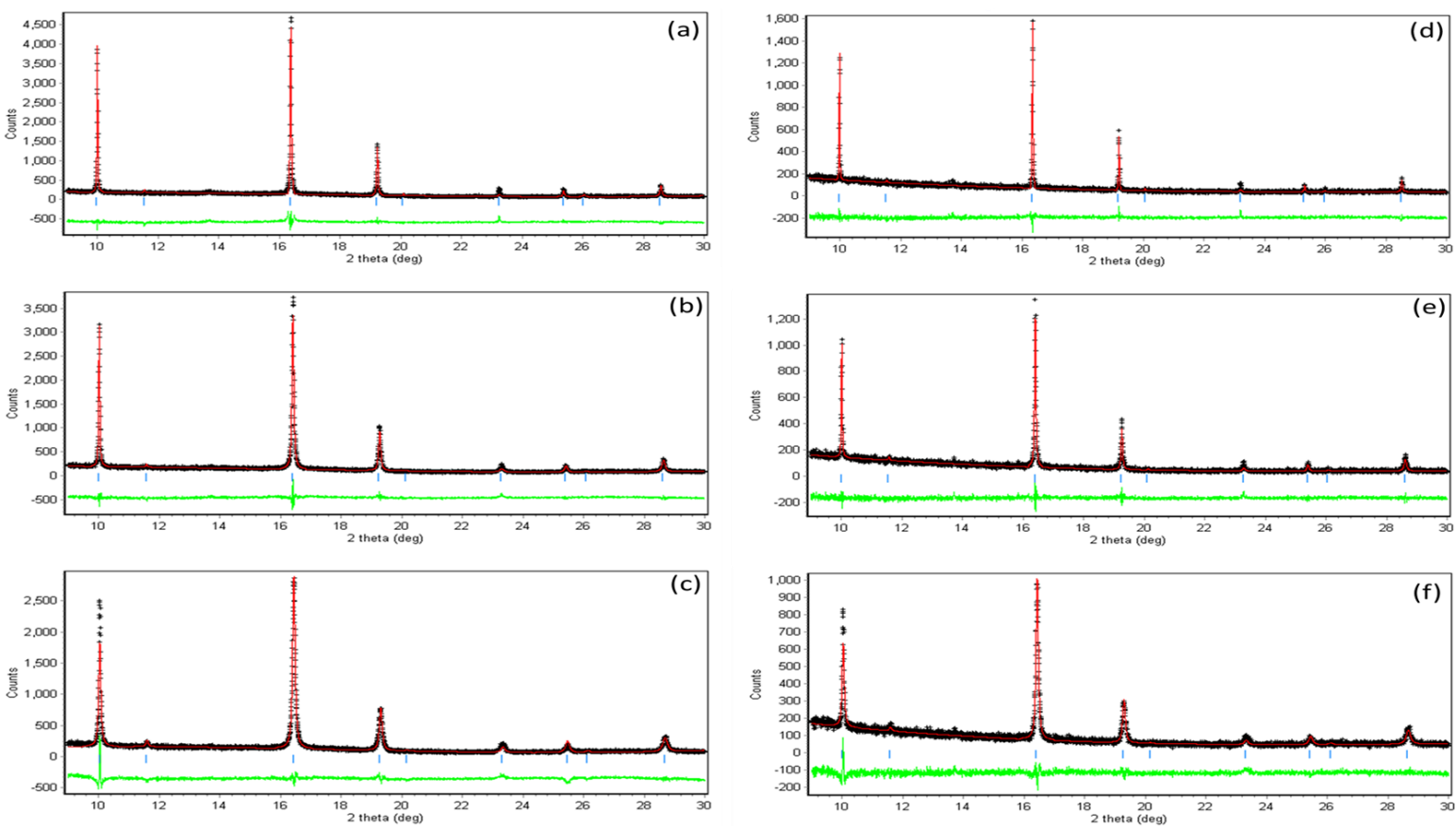

Fig. S2 Rietveld refinement of 0.42 wt $\%$ boron doped $\mathrm{Cu}_{2} \mathrm{Se}(\mathrm{a}-\mathrm{c})$ and undoped $\mathrm{Cu}_{2} \mathrm{Se}$ (d-f) at $624 \mathrm{~K}, 512 \mathrm{~K}$, and $403 \mathrm{~K}$, respectively. The refined parameters are shown in Table S1. 
Table S1 Parameters for the refinement of boron doped and undoped $\mathrm{Cu}_{2} \mathrm{Se}$ at $624 \mathrm{~K}, 512 \mathrm{~K}$, and 403 K. $R_{\mathrm{p}}$ and $R_{\mathrm{wp}}$ are the profile and weighted profile R-factors, respectively, and $\chi^{2}$ is the goodness-of-fit.

\begin{tabular}{|l|l|l|l|l|l|}
\hline Temp (K) & \multicolumn{1}{|r|}{ Lattice parameter } & & & \\
& Sample & a $(\AA)$ & $\mathrm{R}_{\mathrm{p}}$ & $\mathrm{R}_{\mathrm{wp}}$ & $\chi^{2}$ \\
\hline 624 & (a) $0.42 \mathrm{wt} \%$ Boron & 5.85070 & 9.867 & 13.313 & 2.609 \\
\hline 512 & (b) $0.42 \mathrm{wt} \%$ Boron & 5.83880 & 8.560 & 11.077 & 1.853 \\
\hline 403 & (c) $0.42 \mathrm{wt} \%$ Boron & 5.82770 & 9.858 & 12.999 & 2.579 \\
\hline 624 & (d) $\mathrm{Cu}_{2} \mathrm{Se}$ & 5.86110 & 9.777 & 12.962 & 1.242 \\
\hline 512 & (e) $\mathrm{Cu}_{2} \mathrm{Se}$ & 5.84270 & 9.325 & 12.175 & 1.157 \\
\hline 403 & (f) $\mathrm{Cu}_{2} \mathrm{Se}$ & 5.83160 & 9.517 & 12.165 & 1.283 \\
\hline
\end{tabular}



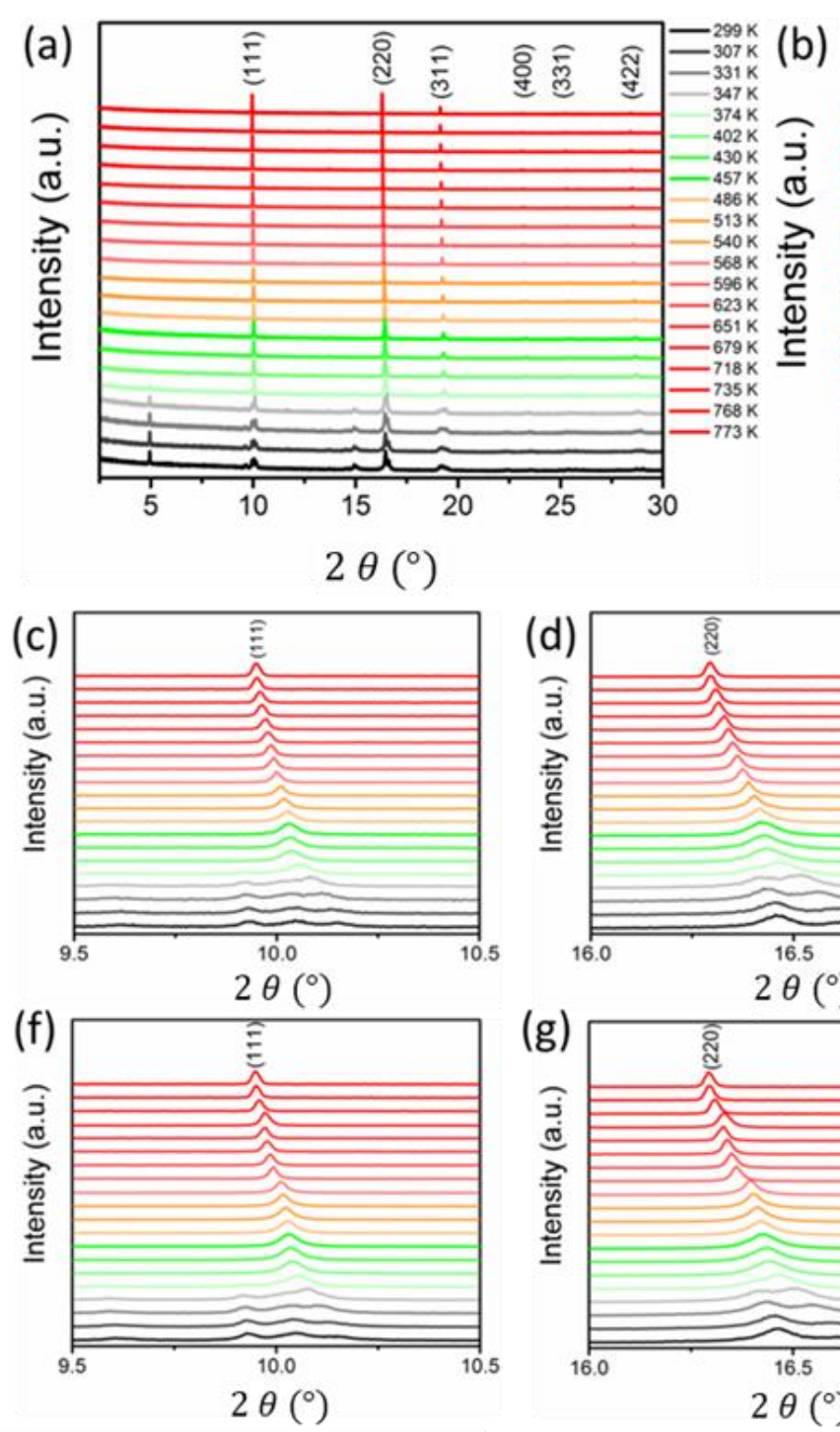
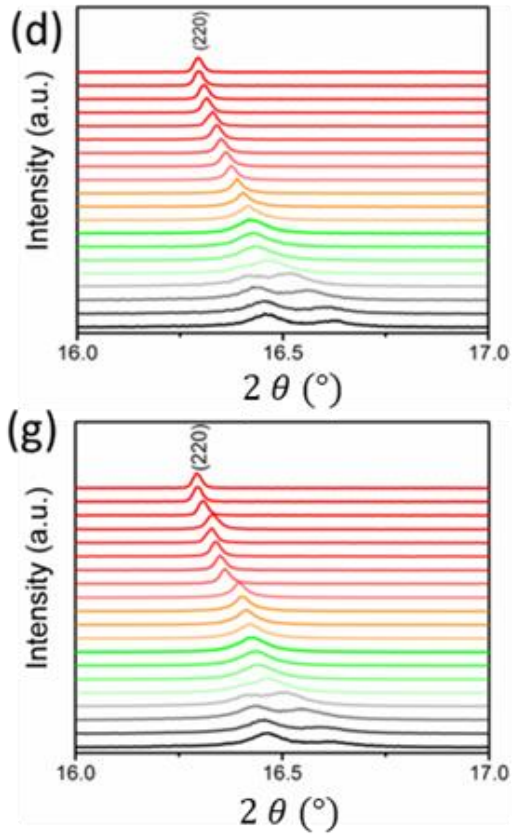
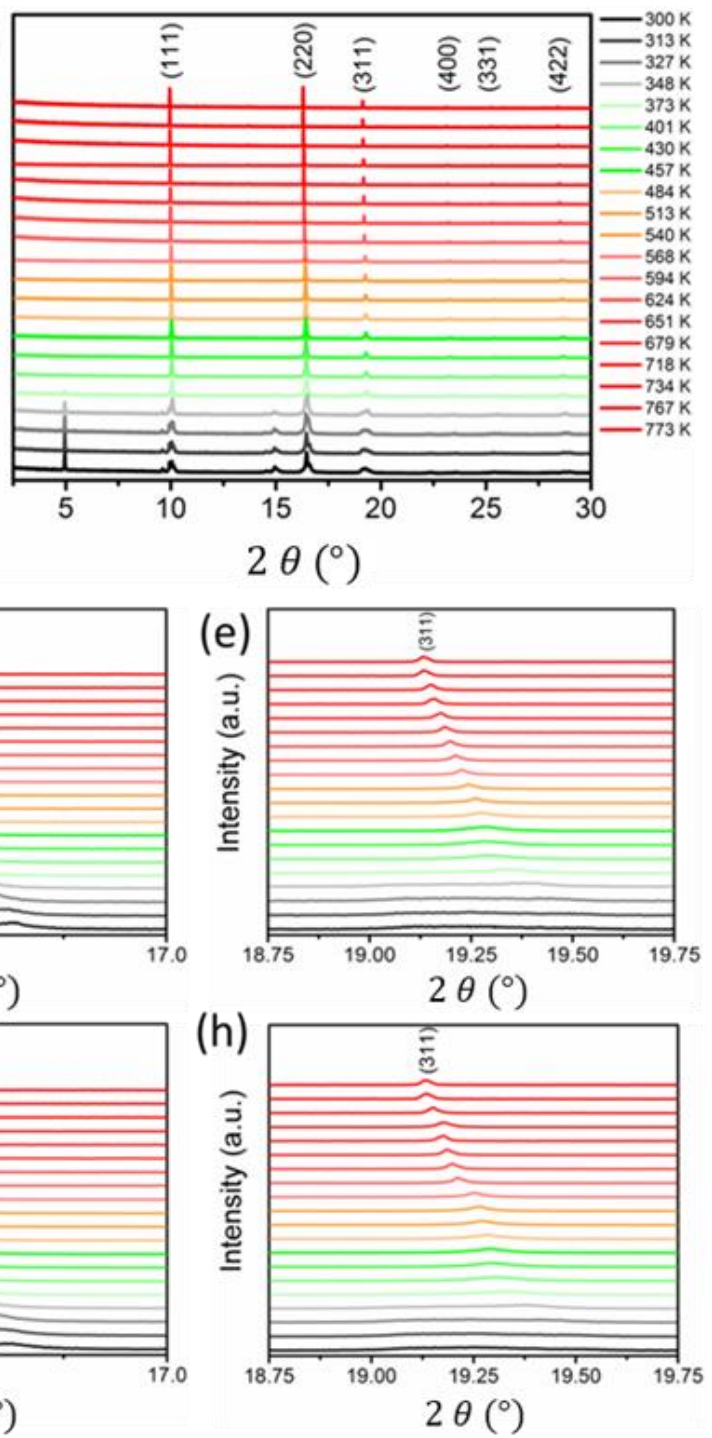

Fig. S3 Synchrotron powder diffraction patterns over the entire measured temperature range of $\sim 300-773 \mathrm{~K}$ for $2 \theta=$ (a) $2.5^{\circ}-30^{\circ}$ (Undoped), (b) $2.5^{\circ}-30^{\circ}$ (0.42 wt $\%$ Boron) (c) $9.5^{\circ}-$ $10.5^{\circ}$ (Undoped), (d) $16^{\circ}-17^{\circ}$ (Undoped),( e) $18.75^{\circ}-19.75^{\circ}$ (Undoped), (f) $9.5^{\circ}-10.5^{\circ}$ (Boron), (g) $16^{\circ}-17^{\circ}$ (Boron), (h) $18.75^{\circ}-19.75^{\circ}$ (Boron). The wavelength is $0.5897313 \AA$. 

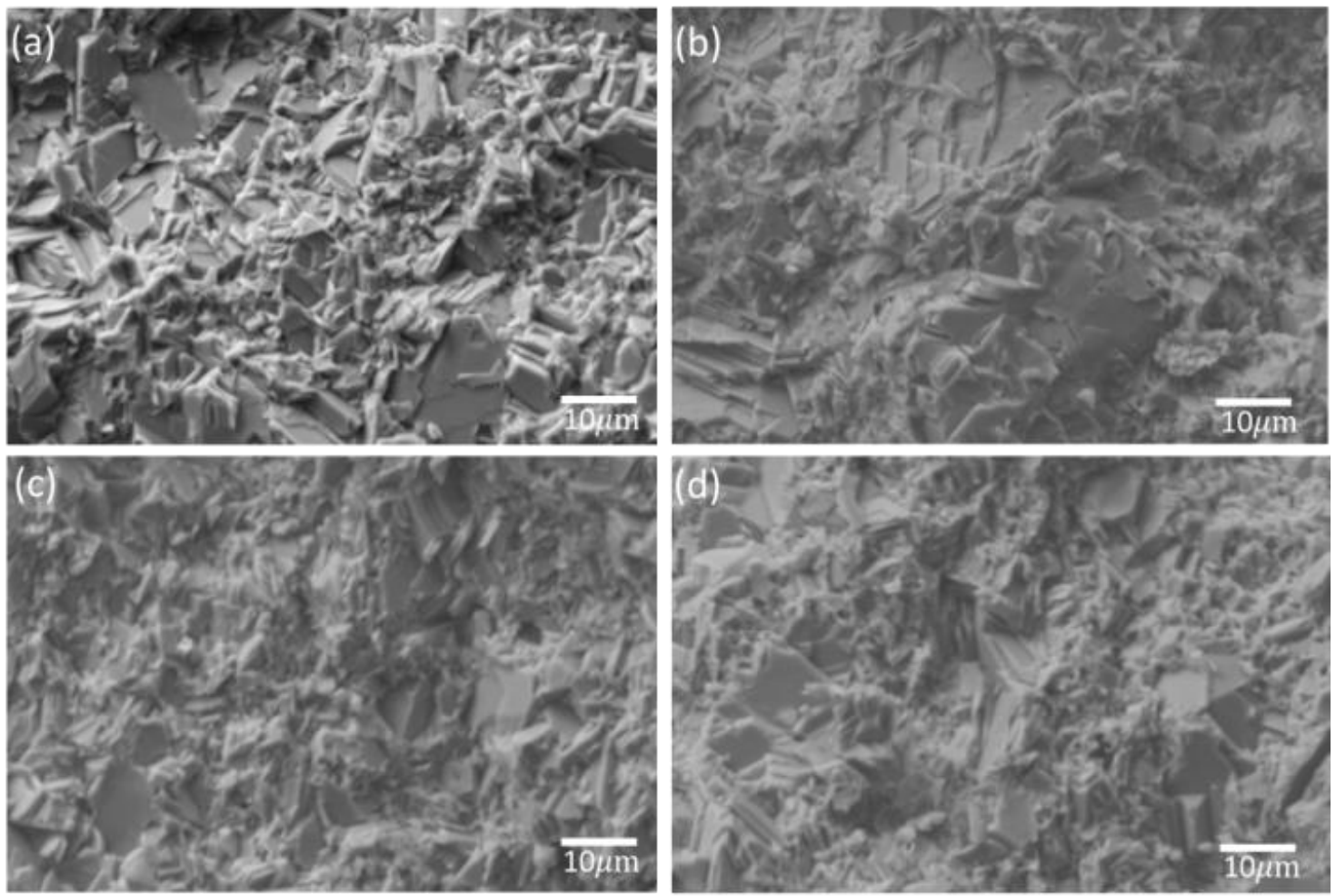

Fig. S4 SEM images of fractured surface morphology of (a) pure $\mathrm{Cu}_{2} \mathrm{Se}$, and b) $0.14 \mathrm{wt} \%$, (c) $0.28 \mathrm{wt} \% \mathrm{~m}$ and (d) $0.42 \mathrm{wt} \%$ boron-doped polycrystalline $\mathrm{Cu}_{2} \mathrm{Se}$ fabricated by the spark plasma sintering (SPS) method. 


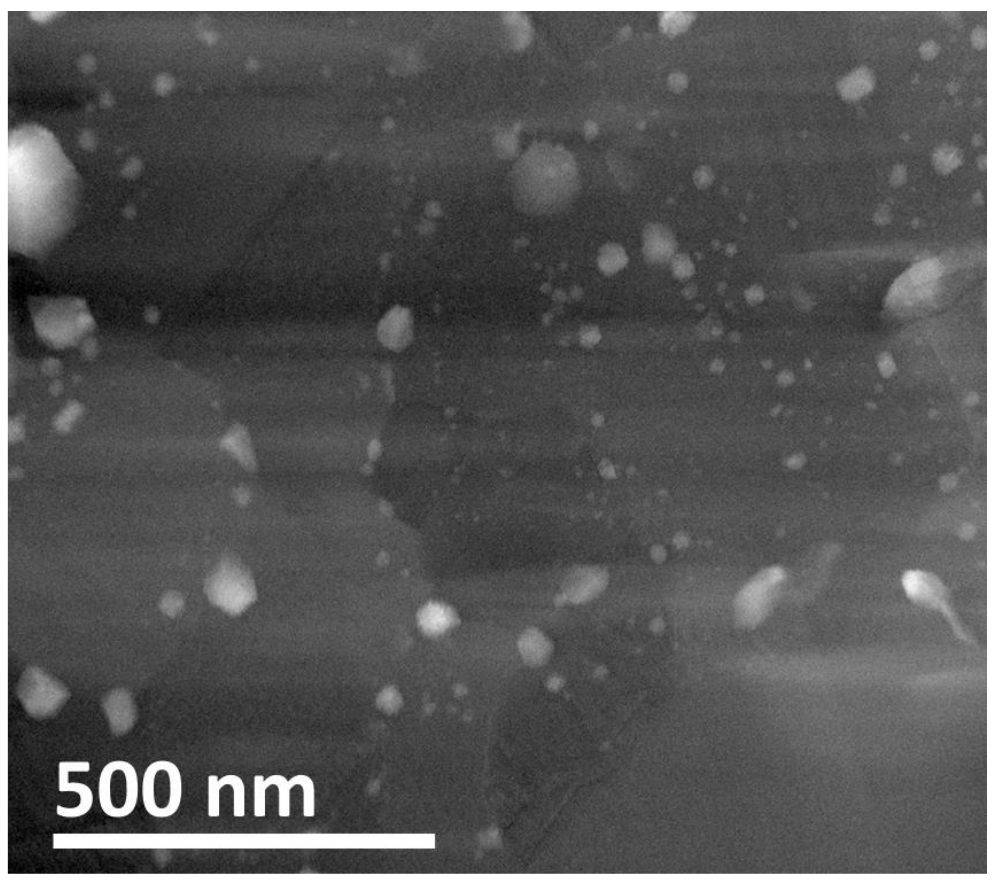

Fig. S5 Low magnification TEM image of the boron doped $\mathrm{Cu}_{2} \mathrm{Se}$ bulk sample showing the presence of boron across the grain boundary 

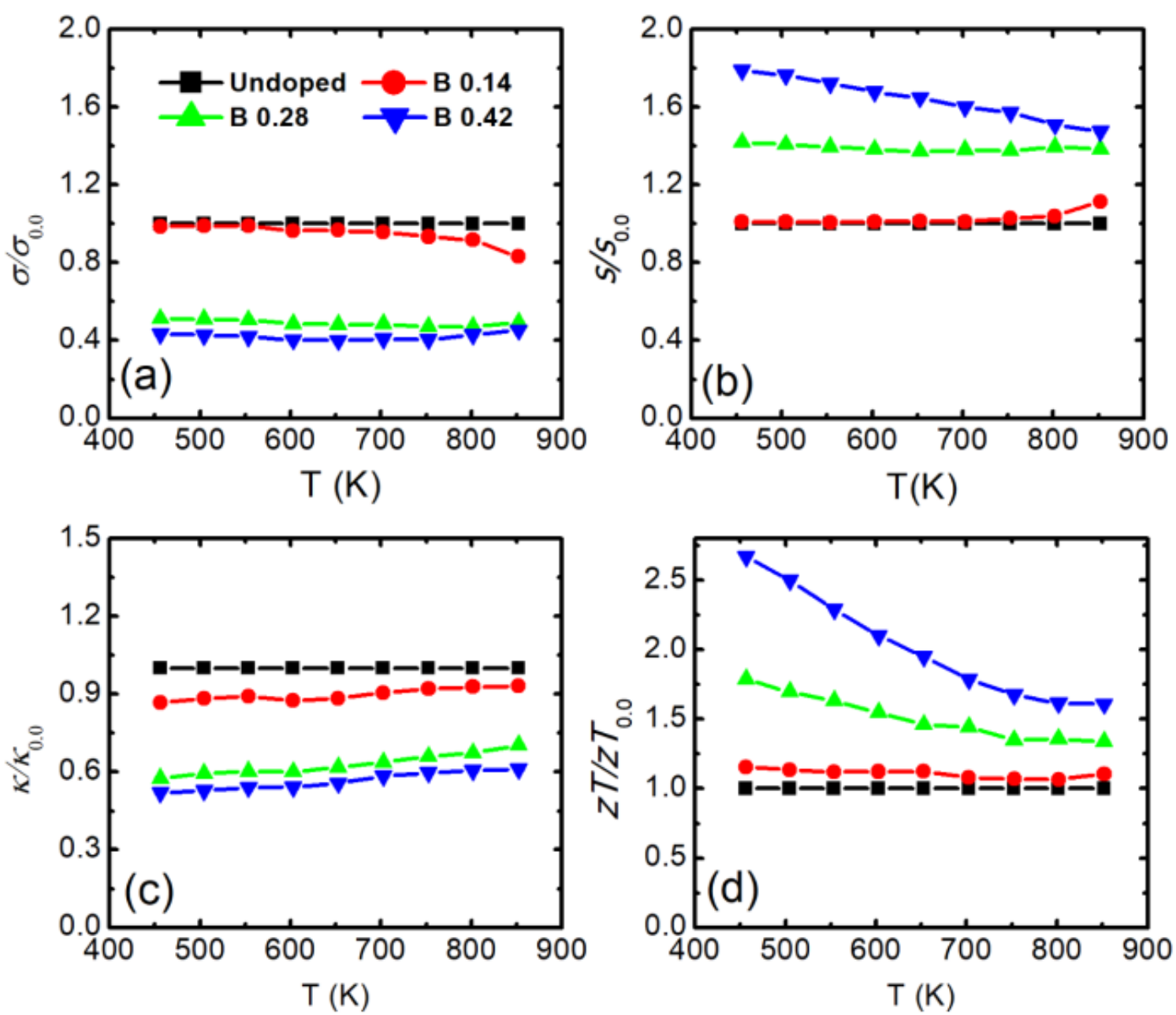

Fig. S6 Temperature dependence of (a) $\sigma / \sigma_{0.0}$, (b) $S / S_{0.0}$, (c) $\kappa / \kappa_{0.0}$, and (d) $z T / z T_{0.0}$ for the boron doped $\mathrm{Cu}_{2} \mathrm{Se}$ samples with doping levels of $0.14,028$, and $0.42 \mathrm{wt} \%$. 

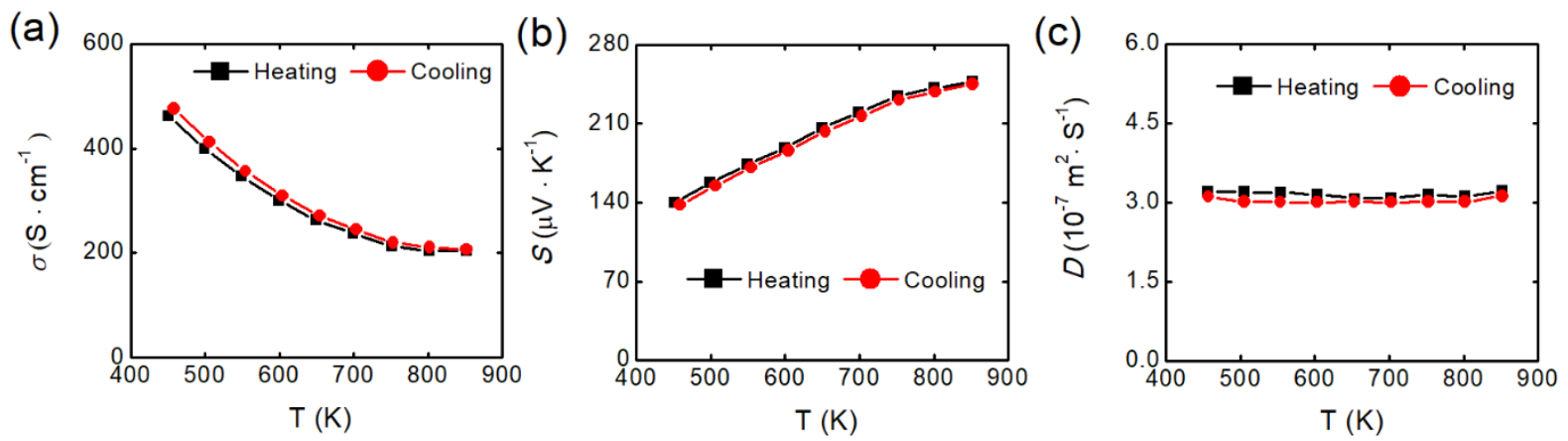

Fig. S7 The electrical and thermal transport properties with respect to temperature during heating up and cooling down for a 0.42 wt.\% Boron doped $\mathrm{Cu}_{2} \mathrm{Se}$ sample: (a) electrical conductivity $(\sigma)$; (b) Seebeck coefficient $(S)$; (c) thermal diffusivity $(D)$. 